\title{
Coke formation of model compounds relevant to pyrolysis bio-oil over ZSM-5
}

Shoucheng Du, ${ }^{[a]}$ David P. Gamliel, ${ }^{[a]}$ Marcus V. Giotto, ${ }^{[b]}$ Julia A. Valla, ${ }^{[a]}$ and George M. Bollas ${ }^{*[a]}$

[a]Department of Chemical \& Biomolecular Engineering, University of Connecticut, Storrs, 191 Auditorium Road, Unit 3222, Storrs, CT 06269, USA.

${ }^{[b]}$ Institute of Materials Science, University of Connecticut, Storrs, 97 North Eagleville Road Unit 3136 Room 011 Storrs, CT 06269-3136, USA.

*Corresponding Author: Tel: +1-860-486-4602. Email: george.bollas@uconn.edu;

\begin{abstract}
Formation of coke during biomass catalytic pyrolysis deteriorates the selectivity to valuable liquid products and deactivates the catalyst, due to pore blocking and active site poisoning. In this work we investigate reaction mechanisms of coke formation and the structure of coke, formed from model compounds of relevance to biomass catalytic pyrolysis. Specifically, toluene, propylene, tolualdehyde and furan are catalytically pyrolyzed over ZSM-5, focusing on their yields to catalytic coke. Pyrolysis over inert silica is also performed, in order to understand the extent of thermal reactions. The pyrolysis product distribution of each model compound is presented and discussed in comparison with coke formation mechanisms proposed in the literature. It is shown that coke is mainly formed via oligomerization and polymerization of aromatic hydrocarbons and olefins. Catalytic reactions enhance the production of coke with higher crystallinity, less condensed structure and higher $\mathrm{H} / \mathrm{C}$ ratio. Catalytic pyrolysis of toluene and tolualdehyde produces coke of similar structure, containing significant amounts of aliphatic carbons. Among the model compounds studied, furan produces the most condensed form of coke with no aliphatic carbons.
\end{abstract}

KEYWORDS: • Heterogeneous catalysis $\bullet$ Biomass $\bullet$ Catalytic pyrolysis $\bullet$ Coke characterization $\bullet$ Coke formation chemistry 


\section{INTRODUCTION}

Fast catalytic pyrolysis of lignocellulosic biomass [1-6], in the presence of zeolite catalysts such as ZSM-5, has been shown to provide enhanced selectivity to aromatic hydrocarbons [5,7-9]. However, not all the carbon in biomass is converted to bio-oil during catalytic pyrolysis, due to the production of carbon oxides $\left(\mathrm{CO}\right.$ and $\mathrm{CO}_{2}$ ), light hydrocarbons (mostly $\mathrm{CH}_{4}, \mathrm{C}_{2} \mathrm{H}_{4}$ and $\mathrm{C}_{3} \mathrm{H}_{6}$ ) and solid residue (char and coke). The production of solid carbonaceous residues not only results in lower carbon selectivity to bio-oil, but is also responsible for catalyst deactivation, which largely impacts product selectivity. Control of coke and char formation during pyrolysis could be possible through novel catalyst and process designs, in which the fundamental understanding of the formation mechanisms of char and coke should be viewed as a prerequisite. The latter requires insight into coke and char structural characteristics and formation chemistry.

In previous work [10], the physicochemical characteristics of coke and char after thermal and catalytic pyrolysis of glucose, cellulose and pine sawdust were investigated. It was shown that char contains oxygen-containing aromatic compounds with carbonyl end groups, whereas coke does not contain carbonyl groups observable with Fourier Transform Infrared Spectroscopy. A comprehensive analysis of coked and charred catalyst samples was performed on the basis of Nitrogen Sorption, Scanning Electron Microscopy and Focused Ion Beam-Scanning Transmission Electron Microscopy. Char was seen to form on the outer surface of the catalyst, thus deactivating the catalyst by surface coverage and macropore blocking. The formation of coke was estimated to occur inside the catalyst micropores, resulting in micropore blockage.

The characteristics of coke and char have also been reported in the open literature. The formation location of char and coke after catalytic upgrading of bio-oil over ZSM-5 was explored by Valle et al. [11]. With temperature programmed oxidation (TPO) of the solid residue, they showed two origins of coke and claimed that catalytic coke is deposited mainly inside the zeolite crystal channels, whereas thermal coke is mostly formed outside of the zeolite crystals. The structure of catalytic coke after catalytic pyrolysis of furan over ZSM-5 was studied by Cheng and Huber [12]. With gel permeation chromatography (GPC), they observed that the 
soluble coke mostly contains polyaromatic compounds with carbonyl groups. The maximum molecular weight of the soluble coke was seen to lie beyond the limitation of the GPC column. Further investigation of the coke structure, specifically the insoluble coke structure, was performed by Guisnet and Magnoux [13]. They claimed that the structure of coke after catalytic cracking of n-heptane over HZSM-5 was similar to that of coronene (pregraphitic), while catalytic cracking of n-heptane over USHY produced coke structures similar to pentacene (linear polyaromatic). The structure of the soluble thermal coke after pyrolysis was studied by Fabbri et al. [14], who found that the main polycyclic aromatic hydrocarbons (PAHs) in the biochar were naphthalene, phenanthrene, fluoranthene, and pyrene. A new method for studying the char structure was proposed by Brewer et al. [15], who performed ${ }^{13} \mathrm{C}-\mathrm{NMR}$ analysis on the solid residue after slow and fast thermal pyrolysis of switchgrass. Quantification of the NMR spectra led to a description of thermal coke as aromatic clusters of 7-8 rings terminated by carbonyl and hydroxyl groups.

Model compounds have been widely used to study the reaction chemistry of coke and char formation [12,16-19]. Typical catalytic coke precursors include aromatic hydrocarbons, aromatic oxygenates, small olefins and small oxygenates. In the literature, the formation of coke during catalytic pyrolysis of small aromatics, such as toluene, was proposed to proceed via selfalkylation reactions [20] and/or side alkylation with propylene [21] under carbenium ion mechanisms. Besides carbenium ion mechanisms, toluene pyrolysis was proposed to proceed via radical reaction mechanisms, leading to coke precursors at high temperature and vacuum $[18,22-24]$. Oxygenated aromatics, such as furan and phenolic compounds, were seen to give rise to significantly different mechanisms of coke formation. Cheng and Huber [12,25] performed catalytic pyrolysis of furan, showing Diels-Alder reaction pathways, followed by oligomerization, cyclization, cracking, isomerization, and hydrogen transfer reactions as the main pathways for coke formation. Catalytic conversion of anisole over ZSM-5 was studied by Prasomsri et al. [26]. They found that catalyst deactivation was due to an anisole condensation process on the active surface, rather than the typical formation of polyaromatic coke. Moreover, Mullen and Boateng [27] performed catalytic pyrolysis of lignin over ZSM-5. They concluded 
that the simple phenols, produced from lignin partial deoxygenation, could not further convert to simple aromatics. Instead, they were likely to be tightly bounded to the active sites of ZSM-5, leading to coke formation and catalyst deactivation. Besides the model compounds that represent aromatic hydrocarbons and aromatic oxygenates, small olefins and oxygenates like propylene [28], acetaldehyde [29], acetic acid [29], ethyl acetate [29] and propanal [30] were also used as model compounds to study the formation of coke during catalytic pyrolysis. A summary of the literature on thermochemical conversion of model compounds that can act as catalytic coke precursors over ZSM-5 is presented in Table S1 [12,25,26,28,30-35].

In this work, we are mainly interested in the formation of coke from compounds that are products of biomass catalytic pyrolysis and at conditions known to maximize the selectivity to aromatics and minimize yields to oxygenated compounds $\left(600{ }^{\circ} \mathrm{C}\right.$ and $\left.1 \mathrm{~atm}\right)$ [3]. We used the existing literature as a guideline for the selection of model compounds of interest and their anticipated reactions. We also used existing knowledge of dominant products from biomass pyrolysis [10] to determine a set of model compounds of relevance to coke formation. We do not focus on primary biomass decomposition reactions, which lead to extensive char formation and substantially different chemistries [36]. Instead, molecules with kinetic diameters smaller than the ZSM-5 largest cavity (7 $\AA$ ), such as toluene, propylene, tolualdehyde, and furan were chosen as representative coke precursors. These four representative model compounds are explored for the identification of reaction pathways of coke formation from aromatics, olefins, aldehydes and oxo-aromatics, respectively. In this study, we chose to use tolualdehyde as the representative aromatic oxygenate with the oxygen on the side chain, because: (1) the presence of tolualdehyde/benzaldehyde in the bio-oil after thermal pyrolysis of biomass has been reported in the literature [37-41]; (2) the oxygen on the side chain, although potentially easily removed by decarbonylation, might contribute to other reactions, such as aldol condensation and/or radical alkylation, affecting coke formation pathways; and (3) to the best of our knowledge, coke formation and characterization from pyrolysis of tolualdehyde has never been the focus of prior work. Coke formation from pyrolysis of phenolic compounds has been studied experimentally to some extent in the literature $[26,27,42,43]$ and is not included in this study. 
The contribution of thermally induced reactions to solid products is analyzed in pyrolysis experiments of the representative model compounds over inert silica. The characteristics of coke from each model compound are analyzed in an effort to reveal the contribution of different functional groups to coke formation. Overall, this study tries to verify existing knowledge on the mechanisms of coke formation, understand the role of oxygen in these reactions, and reveal the coke chemical structure. The main idea and major contribution of this research is to provide evidence for pathways most likely leading to coke formation.

\section{EXPERIMENTAL SECTION}

\subsection{Silica and ZSM-5 catalyst}

Silica from Sigma-Aldrich Corporation was used in the herein considered thermal pyrolysis experiments. Unsupported ZSM-5 zeolite catalyst (CBV 8014) from Zeolyst International, Inc. was used in catalytic pyrolysis experiments. Silica and ZSM-5 of similar particle size were selected to maintain similar bed residence times during the experiments. The Silica and ZSM-5 particles were calcined in air at $550{ }^{\circ} \mathrm{C}$ for 5 hours prior to experiments. The physicochemical characterization of the silica and the ZSM-5 catalyst is shown in Table 1.

Table 1. Physicochemical characterization of the silica and ZSM-5 catalyst used in this work.

\begin{tabular}{|c|c|c|c|c|c|c|c|}
\hline & \multicolumn{2}{|c|}{ Physical property } & \multicolumn{2}{|c|}{ Porosity $^{b}$} & \multicolumn{3}{|c|}{ Acidity } \\
\hline & Qbulk $\left(\mathrm{kg} / \mathrm{m}^{3}\right)$ & $\mathrm{d}_{\mathrm{p}}(\mu \mathrm{m})$ & $\mathrm{S}_{\text {total }}\left(\mathrm{m}^{2} / \mathrm{g}\right)$ & Pore size $(\AA)$ & $\begin{array}{c}\text { B.s. } \\
(\mu \mathrm{mol} / \mathrm{g})\end{array}$ & $\begin{array}{c}\text { L.s. } \\
(\mu \mathrm{mol} / \mathrm{g})\end{array}$ & B.s./L.s \\
\hline Silica & 530 & $0.5 \sim 5$ & 5 & - & - & - & - \\
\hline ZSM-5 & 500 & $0.5 \sim 2$ & 419 & 24 & $133.8[44]$ & $32.7[44]$ & 4.09 \\
\hline
\end{tabular}

\subsection{Experimental setup and procedure}

Experiments with toluene, toluene with propylene, tolualdehyde and furan were performed in a specially designed fixed bed reactor. A schematic representation of the bench scale reactor used in this work is shown in Figure S1. The catalyst bed consisted of silica or ZSM-5 catalyst held in place by two plugs of quartz wool in a quartz tube reactor ( $22 \mathrm{~mm} \mathrm{ID)}$ ). The silica particles were assumed to be inert and these experiments were coined thermal. The reactor was 
heated by a vertical tube furnace to $600{ }^{\circ} \mathrm{C}$, and the bed temperature was controlled with a $\mathrm{K}$ type thermocouple placed in the middle of the catalyst bed. A saturator was used to feed the reactants to the reactor via entrainment with Ar. The saturator temperature was maintained at $10{ }^{\circ} \mathrm{C}$ above the boiling point of the main reactant, measured by a thermocouple. The space velocity of the system was controlled by using Ar as a carrier gas at constant flow rate of 50 sccm.

During the experiments, 3 gr of silica or varying loadings of ZSM-5 (1-3 gr) were placed in the reactor. The reactor was placed inside a tubular furnace with Ar flow until the temperature reached set point. One gram of reactant (toluene, tolualdehyde and furan) was then injected through a septum into the preheated saturator. For the experiments with propylene, 10 vol\% (0.17 gr) propylene in Ar were fed to the reactor for $20 \mathrm{~min}$ and the effect of catalyst to propylene ratio on the product distribution was quantified. In the experiments of propylene with toluene, $1 \mathrm{gr}$ of toluene and $0.17 \mathrm{gr}$ of propylene were co-fed to the reactor. After completion of each experiment, the system was purged with $50 \mathrm{sccm}$ Ar until no other gas could be detected in the MS. The condensable products were collected in an impinger filled with $20 \mathrm{~mL}$ methanol in dry ice. The coked catalyst was removed from the reactor and separated from the quartz wool. An additional $15 \mathrm{~mL}$ of methanol was used to rinse the impinger and the base of the reactor tube to collect any condensates. All liquids were analyzed as discussed in Section 2.3. The repeatability of the experiments was confirmed in standard experiments with toluene and furan at each catalyst to feed ratio, performed at least three times to calculate the experimental standard deviation. The standard deviation was then applied to all the experiments with different model compounds, to present the system error and repeatability of the experiments. The accuracy of each experiment was further screened by its overall mass balance. Only the experiments with $\geq 90 \mathrm{wt} \%$ mass balance were kept and shown here. For the case of catalytic pyrolysis of furan, $\geq 80 \mathrm{wt} \%$ mass balance was accepted due to the presence of water in the liquid product, which was not measured. 


\subsection{Product Analysis and Characterization}

Gas analysis: Gas products were analyzed online with mass spectrometry (MS, Agilent 5975C, inert with triple axis detector). The MS was calibrated using standard gases $\left(\mathrm{H}_{2}, \mathrm{CH}_{4}, \mathrm{CO}, \mathrm{CO}_{2}\right.$, $\mathrm{C}_{2} \mathrm{H}_{4}, \mathrm{C}_{3} \mathrm{H}_{6}$, and $\left.\mathrm{Ar}\right)$.

Liquid analysis: Liquid products were analyzed using an Agilent 6890N Gas Chromatograph equipped with a 5973N mass selective detector (GC-MS) and Agilent DB-5 column. A split ratio of $50: 1$ and temperature program starting at isothermal setting at $40{ }^{\circ} \mathrm{C}$, followed by a $10{ }^{\circ} \mathrm{C} / \mathrm{min}$ ramp to $270{ }^{\circ} \mathrm{C}$ was applied for furan, benzene and toluene quantification. All other compounds were identified with a splitless injection and temperature program starting at $40{ }^{\circ} \mathrm{C}$, followed by a $1{ }^{\circ} \mathrm{C} / \mathrm{min}$ ramp to $87^{\circ} \mathrm{C}$ and a $20^{\circ} \mathrm{C} / \mathrm{min}$ ramp to $270{ }^{\circ} \mathrm{C}$. Quantification standards consisting of furan, benzene, toluene, xylene, styrene, indene, naphthalene, tolualdehyde were calibrated. All other compounds were analyzed using the semi-quantification method $[45,46]$.

Coke Raman spectra: Raman spectra were obtained for the coked catalysts in a Renishaw 2000 Ramanscope, operated with a 0.024 in focus length, $514.5 \mathrm{~nm}$ laser excitation source (2.41 eV), at $20 \%$ power and 32 exposure times, to avoid detector saturation. For each sample, the laser focus was set to $40 \%$ to prevent local damage and 3 different positions were analyzed to verify the spectra. The initial Raman spectra for coked catalysts from all the model compounds show strong signals coming from fluorescence background $[47,48]$, so a consistent baseline correction was performed to the Raman spectra.

Coke Temperature programmed oxidation: The weight percent of coke on catalyst and coke yields were determined with temperature programmed oxidation (TPO) at temperatures up to $900{ }^{\circ} \mathrm{C}$ in a Q-500 thermogravimetric analyzer from TA instruments. All samples were held at $120{ }^{\circ} \mathrm{C}$ for $30 \mathrm{~min}$ in order to remove moisture and then heated to $900{ }^{\circ} \mathrm{C}$ at a heating rate of 15 $\mathrm{K} / \mathrm{min}$ and constant air flow.

Coke Elemental analysis: Elemental analysis of the coked catalysts was performed in a Vario MICRO Elemental Analyzer from Elementar Americas Inc. Prior to each analysis, samples were dried in a vacuum oven at $100{ }^{\circ} \mathrm{C}$ for $3 \mathrm{hr}$. 
Coke DRIFTS analysis: Diffuse Reflectance Infrared Fourier Transform Spectroscopy (DRIFTS) of the coked catalysts was performed in a NICOLET 6700 Fourier Transform Infrared Spectroscopy (FTIR) from Thermo Scientific, equipped with an MCT detector and a Praying Mantis DRIFTS cell from Harrick Scientific. Pure KBr was used as background and samples were diluted in $\mathrm{KBr}(0.5 \mathrm{wt} \%$ concentration) for each analysis.

Coke Solid-State ${ }^{13} \mathrm{C}$ NMR analysis: Solid-state magic angle spinning (MAS) Nuclear magnetic resonance (NMR) spectra were acquired with a Bruker Avance III $400 \mathrm{MHz}$ spectrometer operating at field strength of $9.4 \mathrm{~T}$, corresponding to a frequency of $400 \mathrm{MHz}$ for $1 \mathrm{H}$ and 100.6 $\mathrm{MHz}$ for ${ }^{13} \mathrm{C}$ by using a triple resonance $2.5 \mathrm{~mm}$ MAS probe. Samples were packed in a Zirconia rotor with Vespel caps and spun at $35 \mathrm{kHz}$ at room temperature. Quantitative direct polarization ${ }^{13} \mathrm{C}$ MAS NMR spectra were acquired with $90^{\circ}$ pulse width of $2.5 \mathrm{~s}$, delay time of $120 \mathrm{~s}\left(>5 \mathrm{~T}_{1}\right)$ and $100 \mathrm{kHz}$ of spectral width using spinal 64 high power proton decoupling. Chemical shifts were given with respect to tetramethylsilane (TMS) by using an external reference of glycine (carbonyl at $176.5 \mathrm{ppm}$ ) for ${ }^{13} \mathrm{C}$ as the secondary reference. The coked catalysts were characterized in $\mathrm{NMR}$ without $\mathrm{HF}$ and $\mathrm{CH}_{2} \mathrm{Cl}_{2}$ treatment, in order to measure the lumped characteristics of both soluble and insoluble coke [13].

\section{RESULTS AND DISCUSSION}

\subsection{Pyrolysis selectivity and coke formation pathways}

Toluene, propylene, tolualdehyde and furan were used as representative biomass pyrolysis coke precursors. Pyrolysis experiments were performed at $600{ }^{\circ} \mathrm{C}$ and $1 \mathrm{~atm}$. The results presented in the following are discussed separately for each model compound at these pyrolysis conditions. Firstly, we focused on the selectivity of each model compound and the feasible reaction pathways, on the basis of the products identified. Pyrolysis of the model compounds over inert silica was performed. The product distribution from thermal pyrolysis over silica was compared with that from catalytic pyrolysis over ZSM-5 to verify the existence and understand the extent of catalytic and thermal reactions. Subsequently, we analyzed the physicochemical 
properties of the solid products formed in each experiment and propose chemical structures for the coke produced.

\subsubsection{Coke formation from catalytic pyrolysis of toluene}

Figure 1 (a) presents the product yields from thermal and catalytic pyrolysis of toluene using silica and ZSM-5. Coke formation was promoted by catalytic reactions, with a parallel decrease in the liquid yield. The promotion of coke formation at higher catalyst to feed ratio is consistent with the literature [49-52] and also prior knowledge obtained from the catalytic cracking of hydrocarbons $[53,54]$. Coke is primarily a catalytic product, with only minimal amounts formed from high temperature polymerization. Increasing catalyst to feed ratio enhances catalytic reactions, leading to increased rates of catalytic coke formation. Minor amounts of carbonaceous solid residue, termed here as "thermal coke", are produced via thermal pyrolysis (over silica). Comparison of the TPO of the thermal coke from experiments with silica with that of the catalytic coke from experiments with ZSM-5 shows slightly different oxidation temperature peaks (Figure $1(b)$ ). This difference in oxidation temperatures can be attributed to the different thermal coke and catalytic coke chemical compositions or physical structures, indicating different mechanisms for their formation. Nonetheless, the formation of thermal coke is minor, compared to the catalytic coke, the latter being a clear, strong function of the toluene to catalyst ratio.

Figure 1 (c) shows the liquid product selectivity of thermal and catalytic pyrolysis of toluene. Thermal pyrolysis favors the production of benzene, styrene and biphenyls, with almost no production of xylene, indenes, naphthalenes and benzene derivatives. In catalytic pyrolysis of toluene, the selectivity to xylenes, indenes, benzene derivatives, and biphenyls decreases as the catalyst to toluene ratio increases, which implies their possible role as intermediates for the formation of other compounds, like naphthalenes and coke. The selectivity to heavy PAHs ( $\geq 3$ rings) is lower at higher catalyst to toluene ratios, with a parallel enhancement of coke production. Benzo[a]fluorene (kinetic diameter $7.41 \AA$ [7]), triphenylene (kinetic diameter $7.54 \AA$ [7]) and pyrene (kinetic diameter $7.24 \AA$ [7]) were the bulkier liquid product molecules 
observed. The kinetic diameters of these three compounds are close to the pore constrains of ZSM-5 (largest cavity $7 \AA$, pore limiting diameter $5 \AA$ [55]).
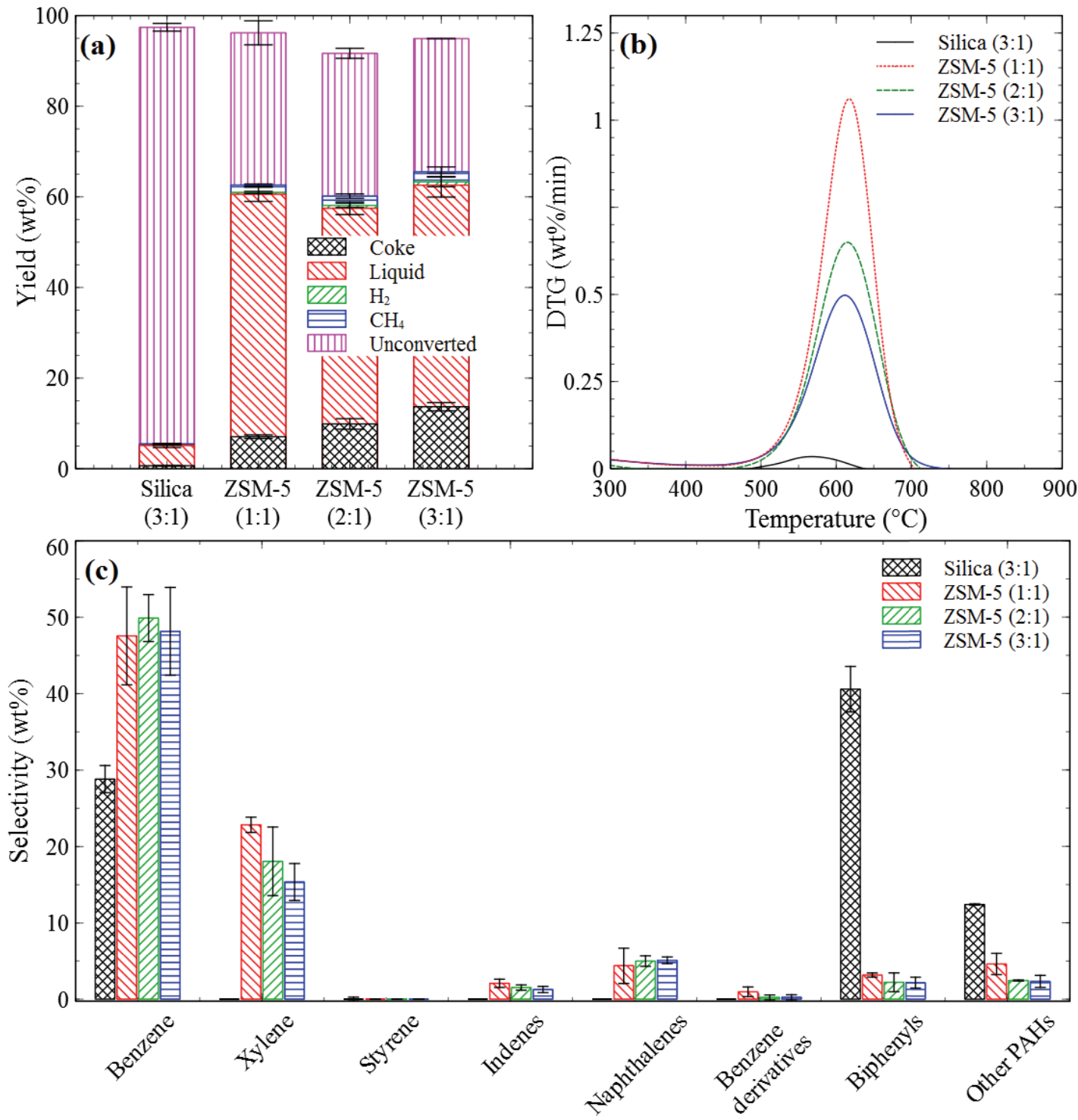

Figure 1. Thermal and catalytic pyrolysis of toluene over silica and ZSM-5: (a) product distribution in yield, (b) TPO of solid product, (c) liquid product selectivity. Liquid product selectivity is defined as the mass of the liquid compound over total mass of all the products (unconverted feed is not included). Indenes include indene, 1-methylindene; Naphthalenes include 2-methylnaphthalene, 1-methylnaphthalene, 2,6-dime-thylnaphthalene; Benzene derivatives include 1,2,3-trimethyl-benzene, 1,3,5-trimethylbenzene, 1-ethenyl-3methylbenzene; Biphenyls include biphenyl, 2-methyl-1,1'-biphenyl, 4-methyl-1,1'-biphenyl, 2,2'-dimethylbiphenyl， 3,3'-dimethyl-biphenyl， 4,4'-dimethylbiphenyl， 2,3'-dimethyl-1,1'biphenyl, diphenylmethane, Bibenzyl, (E)-Stilbene; Other PAHs include fluorene, 2-methyl-9H- 
fluorene, 3-methyl-9H-fluorene, 2,3-dimethyl-9H-fluorene, 1,1'-methyl-enebis[4methyl]benzene, 1-methyl-2-[(3-methylphenyl)me-thyl]benzene, anthracene, 2methylanthracene, phenanthrene, 1-methyl-phenanthrene, 4-methylphenanthrene, 9,10dihydro-1-methyl-phenanthrene, 3,6-dimethylphenanthrene, 1a,9b-di-hydro-1HCyclopropa[1]phenanthrene, 2-phenylnaphthalene, diphnyl-ethyne, 2-phenyl-1H-Indene, fluoranthene, 1-methylpyrene.

Scheme 1 presents a summary of relevant studies on the reaction pathways of the formation of PAHs (coke precursors) in toluene pyrolysis at a wide range of conditions, combined with the experimental observations of this study. Zhang et al. [22] studied the reaction pathway through diphenylmethane and fluorene (Scheme 1, R1A) for phenanthrene formation in toluene pyrolysis at 20 Torr and $997-1597{ }^{\circ} \mathrm{C}$. They also proposed a bibenzyl cyclization reaction pathway (Scheme 1, R1C). In agreement with Zhang et al., Matsugi and Miyoshi [23] reported that, for the formation of phenanthrene during the pyrolysis of toluene, the dominant path is through cyclization of bibenzyl (Scheme 1, R1C). The reaction intermediates, diphenylmethane, fluorine and bibenzyl, are all observed in the liquid products of both thermal and catalytic pyrolysis of toluene in this study. This means that the reaction pathways R1A and R1C possibly contribute to both thermal coke and catalytic coke precursors. However, as indicated by the significant decrease in biphenyls and increase in coke yield in the catalytic pyrolysis (Figure 1), the reaction pathways R1A and R1C are more favorable in the presence of ZSM-5. Matsugi and Miyoshi [23] also proposed another reaction pathway leading to phenanthrene through 5ethenylidenecyclopenta-1,3-diene (Scheme 1, R1B), which could not be confirmed by this study. Furthermore, Colket and Seery [24] proposed a reaction mechanism leading to the formation of fluoranthene, which is also seen in the final products of catalytic pyrolysis of toluene in this study. In their pathway, naphthalene is treated as an intermediate participating in radical reactions (Scheme 1, R1D 3\&4). 


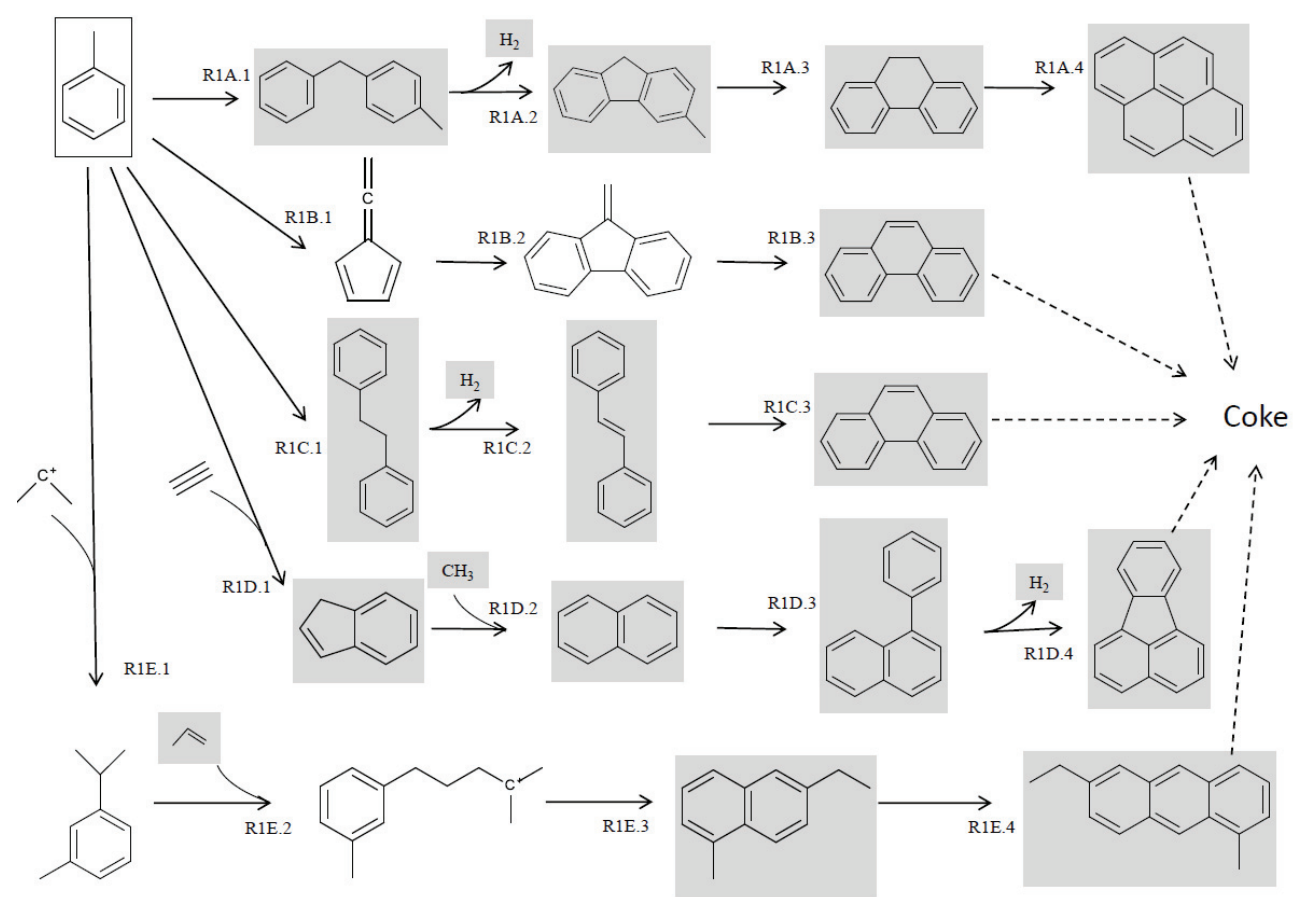

Scheme 1. Reaction pathways for PAH formation from (catalytic) pyrolysis of toluene and toluene with propylene. R1A [20,22] - R1A.1 (toluene self-alkylation), R1A.2 (dehydrogenative coupling), R1A.3 (isomerization) and R1A.4 (hydrogen transfer and repetition of R1A.1-R1A.4); R1B [23] - R1B.1 (isomerization), R1B.2 (fulvenallenyl radical self-alkylation) and R1B.3 (isomerization); R1C [23] - R1C.1 (self-alkylation), R1C.2 (dehydrogenation) and R1C.3 (cyclization); R1D [23,24] - R1D.1 (alkylation and cyclization), R1D.2 (alkylation and ring rearrangement), R1D.3 (alkylation with phenyl radical) and R1D.4 (dehydrogenation); R1E [21] - R1E.1 (alkylation on the nucleus with carbenium ions), R1E.2 (side alkylation and isomerization), R1E.3 (cyclization), and R1E.4 (repetition of R1E.2, R1E.3). The experimentally identified compounds in this study are shown in grey.

Overall, the important reaction intermediates leading to PAH formation identified previously in the literature, such as diphenylmethane, bibenzyl and biphenyl are all observed in the current study, as shown in Scheme 1. The trends of decreasing biphenyls, bibenzyl and heavy PAHs in liquid selectivity as catalyst to feed ratio increases, in addition to higher coke yields, are clear indications of the main coke formation mechanisms R1A and R1C. Coke formation in catalytic pyrolysis of aromatic hydrocarbons mainly proceeds via reactions with biphenyls, bibenzyl and heavy PAHs. These reactions are strongly enhanced by ZSM-5 and absent or slow in thermal pyrolysis experiments. 


\subsubsection{Effect of co-feeding an olefin compound on coke formation}

Figure 2 (a) shows the product yields from catalytic pyrolysis of toluene, co-fed with propylene over silica and ZSM-5. Although the thermal coke yield increases by co-feeding with propylene in thermal pyrolysis, compared with that from pyrolysis of pure toluene, the contribution of thermal reactions to the solid yield during catalytic pyrolysis is still minor, as indicated by the difference in TPO peaks (Figure 2 (b)). Catalytic reactions enhance the conversion of the feed (Figure 2 (a)) and favor the production of benzene, xylene, and naphthalenes (Figure 2 (c)), whereas thermal reactions favor the production of styrene, indenes, benzene derivatives, and biphenyls (Figure 2 (c)). All these observations are consistent with those from pyrolysis of toluene. In catalytic pyrolysis of toluene co-fed with propylene, the conversion of toluene was significantly reduced at relatively low catalyst to feed ratios due to the competitive occupation of the ZSM-5 active sites by propylene. The formation of coke is not enhanced by co-feeding with propylene. Instead, the gas yield is increased in the co-feeding experiments, compared with pure toluene pyrolysis, with a parallel reduction in the liquid product yield. The decrease in liquid selectivity is mostly attributed to smaller yields to xylene and biphenyls, as shown in Figure $1 \& 2$. This means that the presence of propylene in catalytic pyrolysis of toluene restricts the formation of xylene and biphenyls or promotes their conversion to larger aromatics (e.g., naphthalene). This is further verified by comparing the liquid product selectivity from catalytic pyrolysis of propylene and that of toluene with propylene co-fed (Figure S2 in the Supporting Information).

A summary of the possible pathways to coke formation from toluene and propylene is shown in Scheme 1. Quintana et al. [21] proposed an ionic mechanism (Scheme 1, R1E) for the formation pathway of a coke precursor (alkylated phenanthrene) in catalytic cracking of 1-butene over FCC zeolite catalyst at $530{ }^{\circ} \mathrm{C}$. In the mechanism R1E of Scheme 1, propylene is proposed to act as a preferential alkylant agent for the alkylation of toluene. Further alkylation of the resulting alkylated aromatic by propylene leads to coke formation. The reaction proceeds through the formation of an o-cymene intermediate, which was not observed in this work. However, coke formation through o-cymene is still possible if we assume complete conversion of the 
substituted aromatic intermediates. Actually, when alkylation of propylene and toluene occurs at relatively lower temperatures $\left(200-250{ }^{\circ} \mathrm{C}\right)$, cymene is usually observed as liquid product [56,57]. Besides the formation of cymene, the decrease in the yields to xylene and biphenyls and the increase in naphthalene yield are all strong indications of the reaction pathway R1E in Scheme 1.
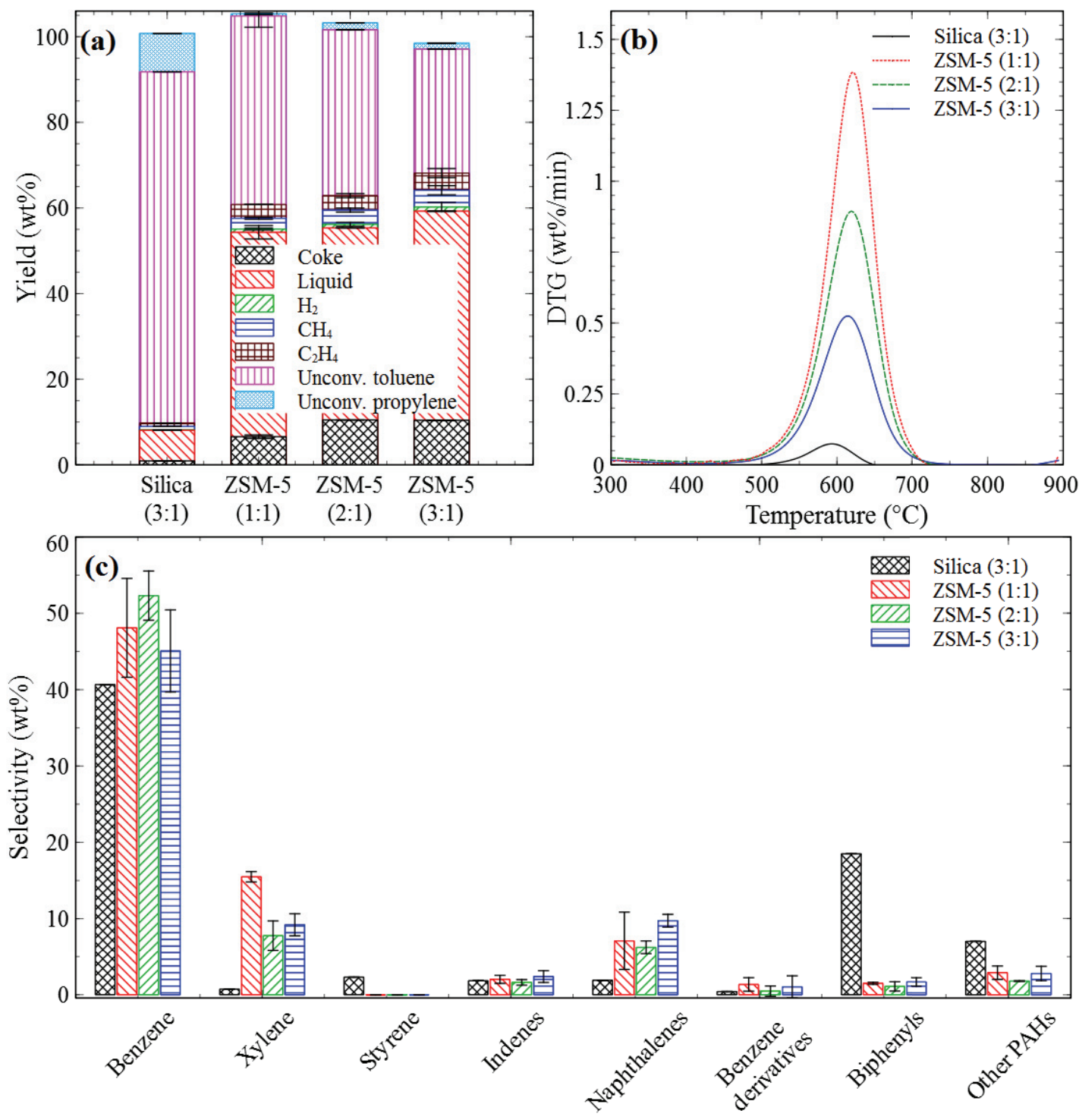

Figure 2. Catalytic pyrolysis of toluene and propylene over silica and ZSM-5: (a) product distribution in yield, (b) TPO of solid product, (c) liquid product selectivity. Liquid product selectivity is defined as the mass of the liquid compound over total mass of all the products (unconverted feed is not included). 


\subsubsection{Contribution of aromatic carbonyl groups to coke formation}

Figure 3 (a) shows the product yields from catalytic pyrolysis of tolualdehyde. Complete conversion of tolualdehyde was observed in thermal and catalytic pyrolysis regardless of the catalyst to feed ratio. Moreover, the production of significant amounts of $\mathrm{CO}$ during both catalytic and thermal pyrolysis of tolualdehyde indicates that decarbonylation occurs at the initial stage of the pyrolysis as a thermal reaction.
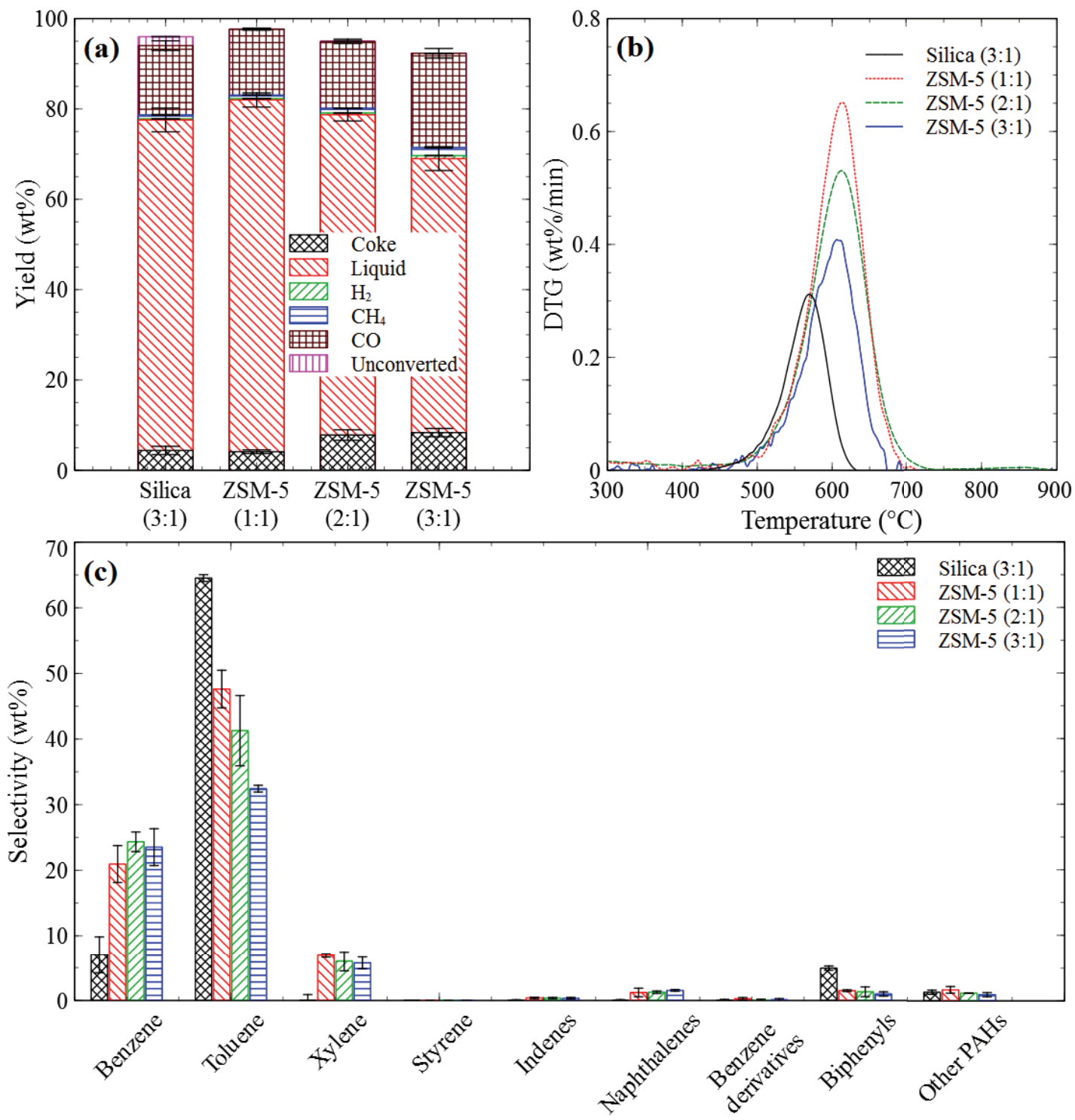

Figure 3. Catalytic pyrolysis of tolualdehyde over silica and ZSM-5: (a) product distribution in yield, (b) TPO of solid product, (c) liquid product selectivity. Liquid product selectivity is defined as the mass of the liquid compound over total mass of all the products (unconverted feed is not included). 
Consistent with the pyrolysis of toluene and toluene plus propylene, coke formation is enhanced as catalyst to feed ratio increases. Interestingly, thermal pyrolysis of tolualdehyde over silica produces more carbonaceous residue in yield than thermal pyrolysis of toluene and toluene plus propylene. The high tendency of aldehyde to form thermal coke was also observed by Gayubo et al. [31]. The TPO results indicate a less condensed form of the thermal coke, compared with that of catalytic coke (Figure 3 (b)). Figure 3 (c) shows the liquid selectivity from thermal and catalytic pyrolysis of tolualdehyde. In thermal pyrolysis of tolualdehyde, toluene, biphenyls, and PAHs are most favorable liquid products, similarly with the trends in thermal pyrolysis of toluene. In catalytic pyrolysis of tolualdehyde, the selectivity to naphthalenes increases as catalyst to feed ratio increases, whereas the selectivity to all other compounds decreases at higher catalyst to feed ratios. This trend is consistent with the liquid product selectivity of toluene catalytic pyrolysis. Overall, by comparing the liquid selectivity of the two reaction systems (toluene and tolualdehyde), qualitatively the same products were measured.

A summary of literature-reported pathways to coke formation from tolualdehyde is shown in Scheme 2. Ausavasukhi et al. [33] studied the catalytic pyrolysis of benzaldehyde over galliumimpregnated ZSM-5. They claimed that benzaldehyde decomposes to benzene and $\mathrm{CO}$ on strong Brønsted acid sites at 450-550 ${ }^{\circ} \mathrm{C}$ (Scheme 2, R2A). However, Hurd and Bennett [58] reported the thermal decomposition of benzaldehyde to benzene and $\mathrm{CO}$ at elevated temperatures $\left(680-690^{\circ} \mathrm{C}\right)$. They also observed the thermal reaction of benzaldehyde to benzyl benzoate (Scheme 2, R2C) by a polymerization reaction at $350-370{ }^{\circ} \mathrm{C}$. According to the current study and the significant amounts of $\mathrm{CO}$ produced from both thermal and catalytic pyrolysis, it is reasonable to claim that decarbonylation occurs at the initial stage of tolualdehyde pyrolysis as a thermal reaction at $600{ }^{\circ} \mathrm{C}$. The thermal cracking of benzaldehyde to phenyl radical, $\mathrm{H}$ and $\mathrm{CO}$ at high temperature $\left(1327^{\circ} \mathrm{C}\right)$ was reported by Vasiliou et al. [59] (Scheme 2, R2B.1). According to their findings, it is likely that, during thermal pyrolysis of tolualdehyde, a 4methylphenyl radical is formed as a reaction intermediate. The 4-methylphenyl radical can readily undergo self-alkylation reactions [18], forming the experimentally observed biphenyl, 
diphenylmethane and coke. This explains the enhanced thermal coke formation at the presence of the formyl groups.

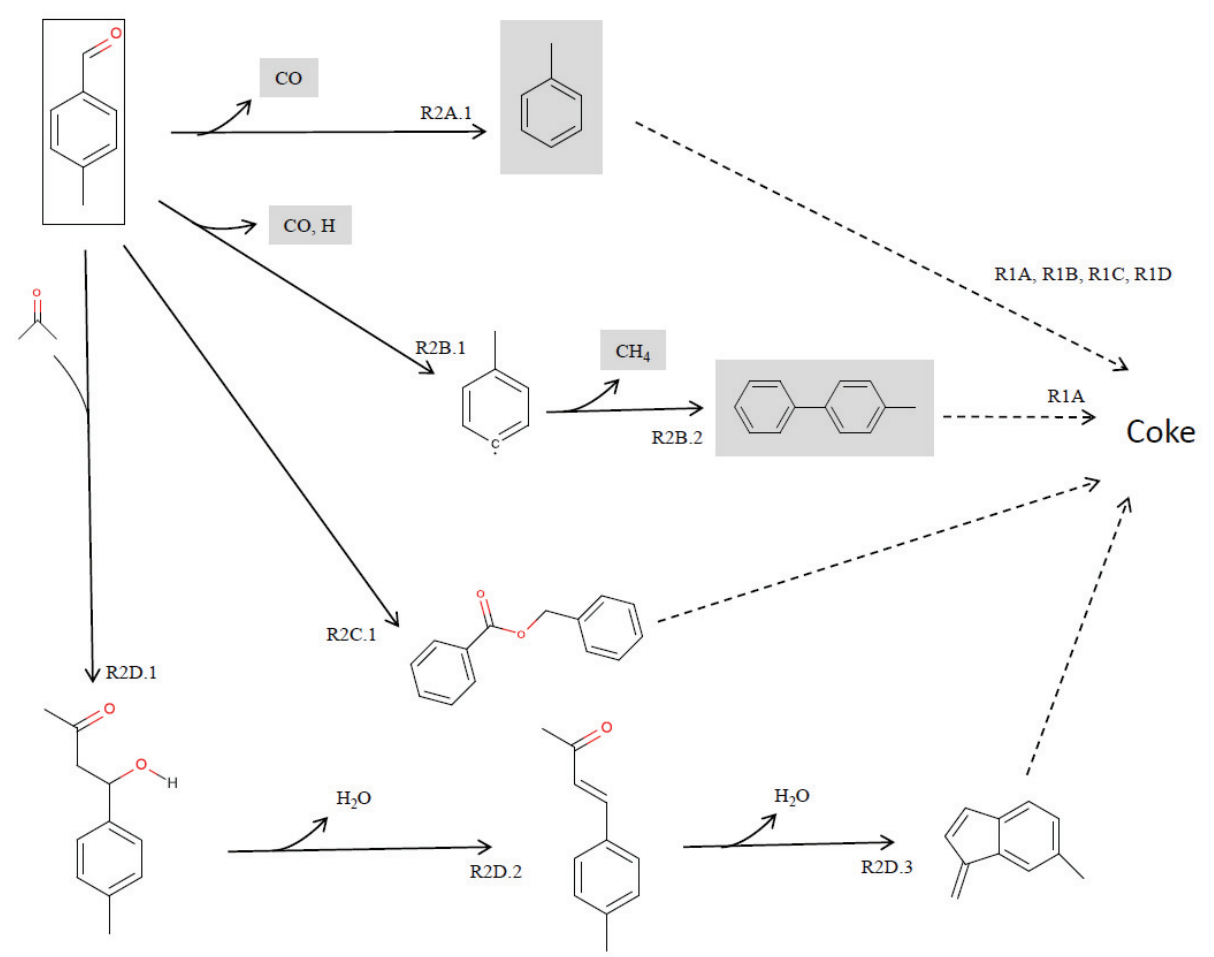

Scheme 2. Reaction pathways of catalytic pyrolysis of tolualdehyde. R2A [33,58] - R2A.1 (decarbonylation); R2B [18,20,59] - R2B.1 (decarbonylation, forming 4-methylphenyl radical), R2B.2 (self-alkylation); R2C [58] - R2C.1 (polymerization); R2D [60] - R2D.1 (aldol condensation), R2D.2 (dehydrogenation), R2D.3 (dehydration, cyclization). The experimentally identified compounds in this study are shown in grey.

In Scheme 2, R2D, aldol condensation of tolualdehyde and acetone is also suggested as the initial reaction for aromatics production and eventually leads to coke. Mettler et al. [61] discussed the role of aldol condensation in the formation of pyrolysis char. There might exist a connection between char formation during pyrolysis $\left(400-600{ }^{\circ} \mathrm{C}\right)$ and humin formation during aqueous phase conversion at low temperature $\left(<200{ }^{\circ} \mathrm{C}\right)$. Since the formation of humin through aldol condensation during aqueous phase conversion of biomass and biomass-derivatives is well accepted [62-64], it is of interest to explore if formation of pyrolysis char also follows the aldol condensation route. On the basis of the liquid and solid yields of Figure 3, decarbonylation is seen as the dominant reaction in tolualdehyde pyrolysis at $600{ }^{\circ} \mathrm{C}$. Aldol condensation is not likely to occur at $600{ }^{\circ} \mathrm{C}$ during pyrolysis. 


\subsubsection{Coke formation from an aromatic oxygenate compound}

Oxygenates and in particular furanic compounds are predominant in the liquid product of biomass pyrolysis. In this work, furan, a proven important biomass pyrolysis intermediate $[12,65]$ was used as a model compound for the study of coke formation from aromatic oxygenates.

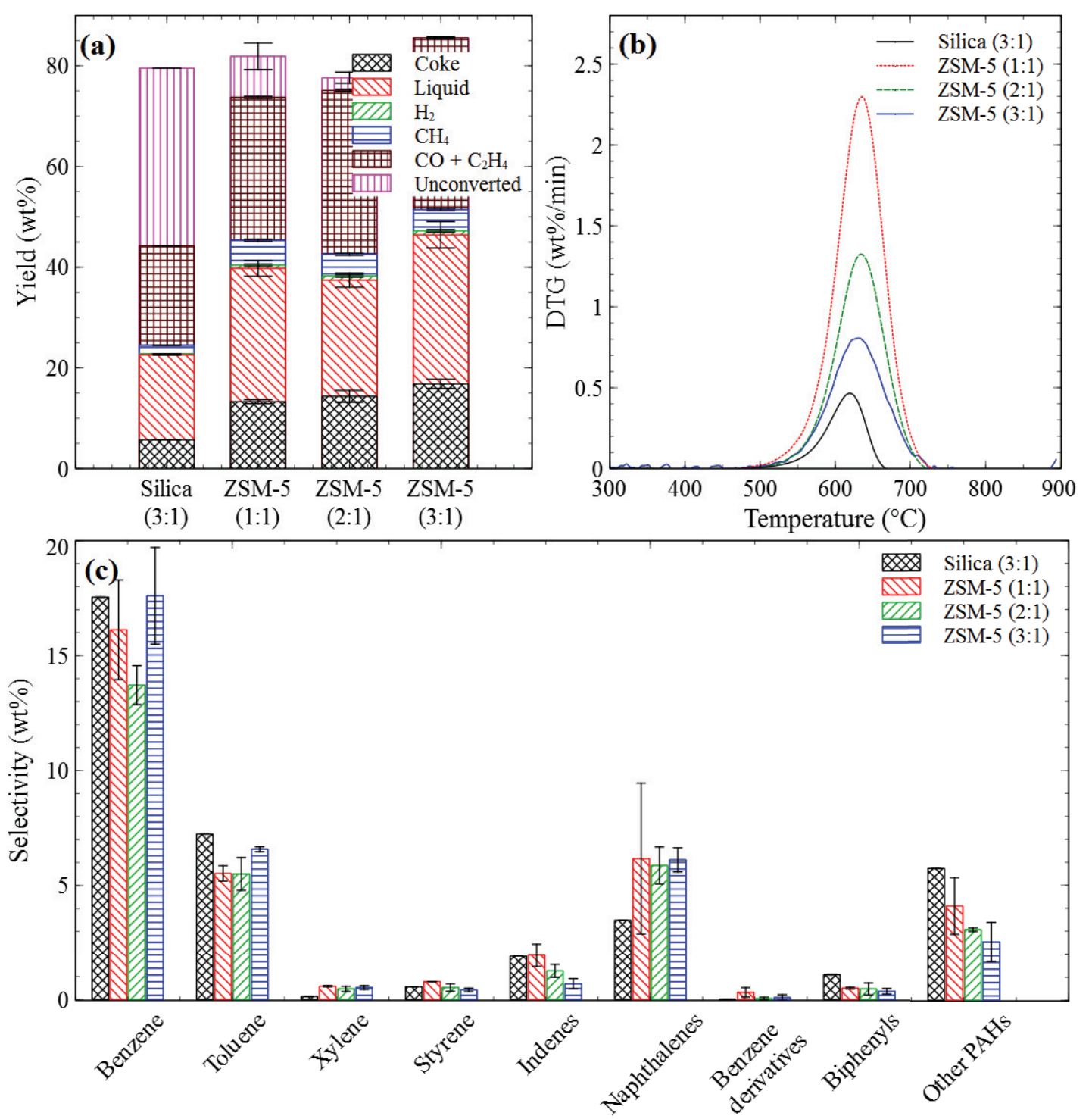

Figure 4. Catalytic pyrolysis of furan over silica and ZSM-5: (a) product distribution in yield, (b) TPO of solid product, (c) liquid product selectivity. Liquid product selectivity is defined as the mass of the liquid compound over total mass of all the products (unconverted feed is not included). 
As shown in Figure 4 (a), thermal pyrolysis of furan produces significant amounts of solid carbonaceous residues. The extent of thermal reactions leading to solid products in catalytic pyrolysis is not small, as indicated by the oxidation temperature peaks in the TPO of thermal and catalytic solid residues (Figure 4 (b)). Coke formation is enhanced by increasing catalyst to feed ratio. The overall selectivity to coke in the products from furan pyrolysis is much higher than that from toluene pyrolysis. The mass balance of catalytic pyrolysis of furan is in the range of $80-85 \%$, due to the production of water, which was not measured. As shown in Figure 4 (c), the liquid products identified from catalytic pyrolysis of furan were also observed in the liquid from thermal pyrolysis. Compared with thermal pyrolysis, the decreased selectivities to styrene, indenes, naphthalenes, biphenyls and PAHs in catalytic pyrolysis, especially at higher catalyst to feed ratios, indicate that these compounds are important catalytic coke precursors. It was previously proposed that the production of aromatics from pyrolysis of furan over ZSM-5 follows Diels Alder and ring-opening pathways $[12,25,66]$. Here we observe that these reactions are also responsible for carbon formation.

Scheme 3 summarizes the pathways proposed in the literature for the formation of coke from furan. In the reaction pathways proposed by Cheng and Huber [25], coke formation in the catalytic pyrolysis of furan mostly begins from aromatic hydrocarbons and/or olefins of the socalled "hydrocarbon pool" (Scheme 3, R3A). The hydrocarbon pool mechanism was originally proposed for the conversion of methanol to aromatics with ZSM-5 [67,68]. It was proposed that methanol enters this "hydrocarbon pool" within the zeolite framework where it becomes an adsorbate $\left(\mathrm{CH}_{2}\right)_{\mathrm{n}}$. The adsorbate then continually produces aromatics and olefins following a parallel mechanism, by interacting with reactants and products. A similar mechanism is surmised here for furan. Although furan is an aromatic oxygenate, the oxygen in furan does not directly contribute to the structure of coke in this pathway and coke should not contain oxygen in the form of carbonyl or hydroxyl groups. Another possible reaction pathway (Scheme 3, R3B) is the furan hydrolysis, suggested by Gilbert et al. [69]. Furan reacts with water to produce $\mathrm{CO}_{2}$ 
and olefins. It is very likely that coke formation in this pathway follows that of the aforementioned in the catalytic pyrolysis of olefins (Scheme 1, R1E).

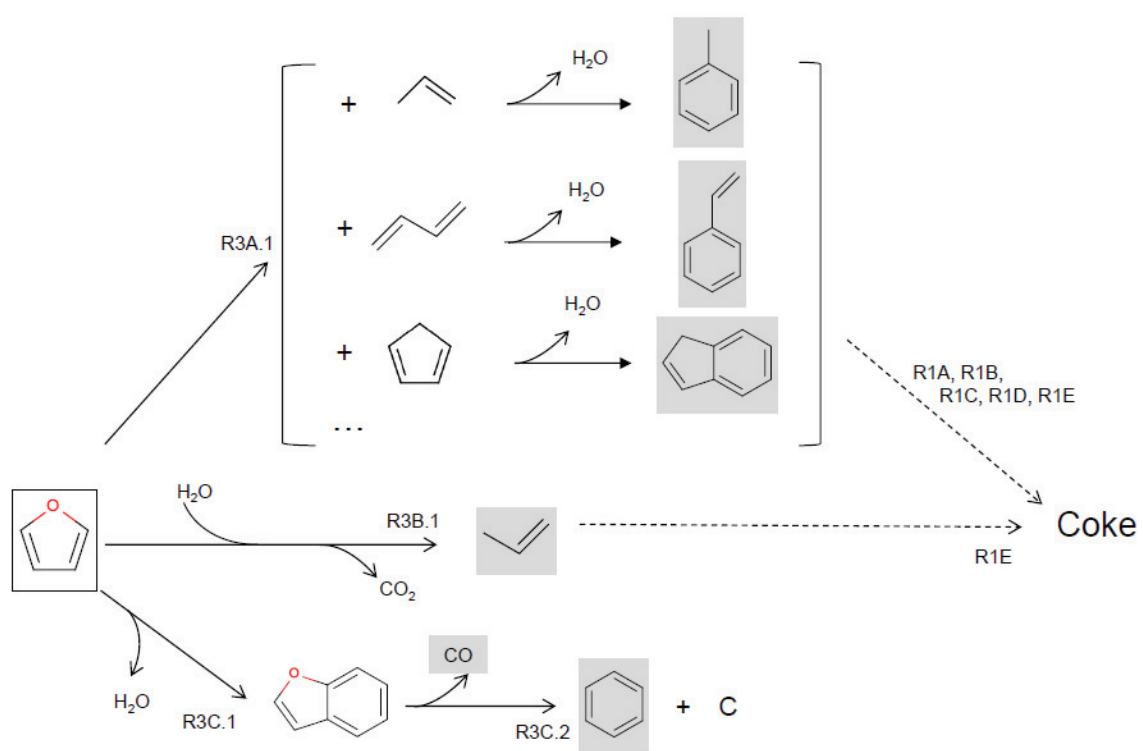

Scheme 3. Reaction pathways for catalytic pyrolysis of furan. R3A [25] - R3A.1 (Diels Alder to form the "hydrocarbon pool"); R3B [69] - R3B.1 (hydrolysis); R3C [25] - R3C.1 (furan selfcondensation), R3C.2 (decarbonylation and cracking). The experimentally identified compounds in this study are shown in grey.

Overall, the coke formation pathways, R3A and R3B, suggest that coke formation in furan catalytic pyrolysis was of the same origins as that in the pyrolysis of hydrocarbons. However, a different pathway comes from furan self-condensation (Scheme 3, R3C). This pathway is specific to the pyrolysis of furan and reflects the contribution of oxygen in the formation of coke. In this scheme, furan reacts with itself, forming water and benzofuran via ring opening [66]. Subsequently, benzofuran decomposes to benzene, coke and CO [25]. According to the reaction stoichiometry, the coke shown in this mechanism contains mostly carbon. Further characterization in the following section confirms that the coke from pyrolysis of furan has a highly condensed form compared with that from pyrolysis of other model compounds used in this study, thus verifying the pathway of Scheme 3, R3C. Overall, the classic compounds of the "hydrocarbon pool", such as propylene, benzene, and other aromatic hydrocarbons, were identified in the liquid product of furan pyrolysis. This confirms the validity of all the coke formation pathways of Scheme 3 in the catalytic pyrolysis of furan. 


\subsection{Physicochemical characterization of coke from pyrolysis of different model compounds}

In the previous section, possible reaction pathways for each model compound studied were discussed. It was seen that coke formation is highly related to alkylation and hydrogen transfer reactions of aromatic hydrocarbons and olefins. In this Section, TPO and elemental analysis are used for the analysis of the $\mathrm{H}$ and $\mathrm{C}$ content in coke. Raman, DRIFTS and solid-state ${ }^{13} \mathrm{C}$ NMR are used for the analysis of physicochemical properties and coke structure.

\subsubsection{Raman analysis}

Figure 5 shows the Raman spectra of the coked catalysts from catalytic pyrolysis of toluene, toluene/propylene, tolualdehyde and furan at $600{ }^{\circ} \mathrm{C}$ and 1:1-3:1 catalyst to feed ratios. Deconvolution of the Raman spectra and assignment of each component to different carbon properties has been the focus of previous work [70,11], as well as our previous study [10]. Here, we simply focus on the crystallinity of the coke structure under different pyrolysis conditions. According to Schwan et al. [71], the D peak corresponds to the existence of condensed benzene rings incorporated in the amorphous (hydrogenated) structure or highly disordered graphitic structure. The $\mathrm{G}$ peak stands for $E_{2 \mathrm{~g} 2}$ mode of graphite or the $\mathrm{C}=\mathrm{C} \mathrm{sp}^{2}$ stretching of olefinic or conjugated carbon chains. The broadening and position shift of the Raman $\mathrm{G}$ peaks are related to the integrated effects of carbon cluster size, distribution, stress, and chemical bonding [72]. Table S3 summarizes the deconvolution peak areas for the G and D bands. The ratio of the two bands, $\mathrm{I}_{\mathrm{D}} / \mathrm{I}_{\mathrm{G}}$, for all the samples is within the range of $0.5-1.5$. Analysis of the ratio of the $\mathrm{G}$ and $\mathrm{D}$ bands and the $\mathrm{G}$ band line width of $100-150 \mathrm{~cm}^{-1}$ for all the samples (Figure 5) shows that the coke from pyrolysis of all the model compounds used in this study contains amorphous hydrogenated carbon structures (see Figure 5 in Ref. [71]). 

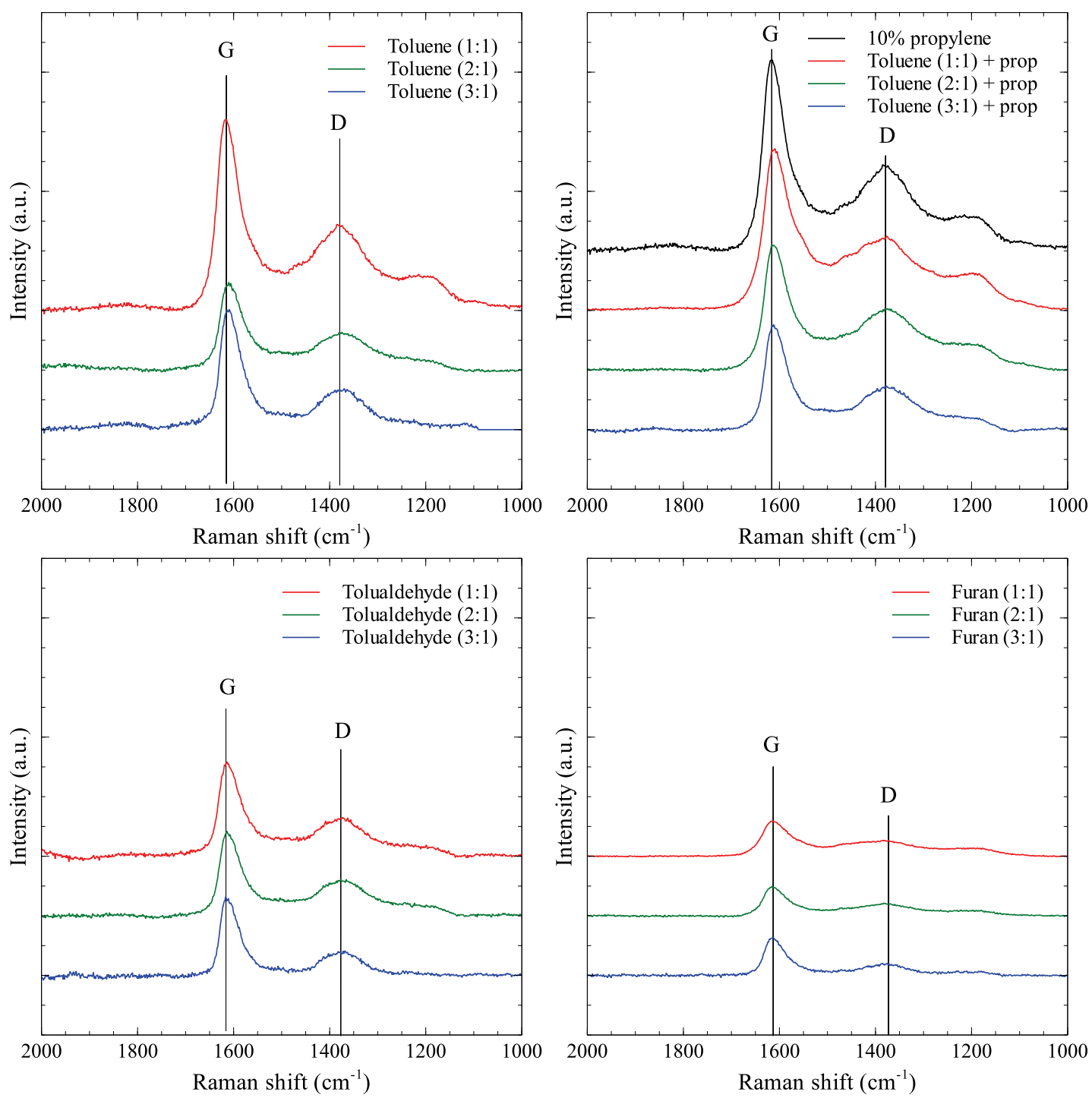

Figure 5. Normalized Raman spectra of coked catalysts from catalytic pyrolysis of toluene, toluene/propylene, tolualdehyde and furan using ZSM-5 at $600{ }^{\circ} \mathrm{C}, 1: 1-3: 1$ catalyst to feed ratios.

\subsubsection{TPO and elemental analysis}

Figure $6(a, b)$ presents the temperature of the peak of the first differential thermogram (DTG) of the coked catalysts, and their $\mathrm{H} / \mathrm{C}$ molar ratio from elemental analysis as a function of catalyst to feed ratio. In Figure 6 (a), the DTG peak temperature decreases as the catalyst to feed ratio increases, indicating a relatively more condensed structure (lower $\mathrm{H} / \mathrm{C}$ molar ratio) at lower catalyst to feed ratios. Small differences are seen in the DTG peaks of the coke from pyrolysis of toluene, toluene plus propylene and tolualdehyde, which can be attributed to the different effective toluene to catalyst ratio. Nonetheless, the consistency in the trends of these results is 
striking. As indicated by the DTG peak temperature, the similar structures of coke from pyrolysis of toluene, toluene plus propylene and tolualdehyde confirm in part the hypothesis that similar mechanisms are responsible for their formation. As shown in R1C, R1E and R2A in Schemes 1 and 2, the coke precursors in the pyrolysis of toluene, toluene plus propylene and tolualdehyde are similar three-ring PAHs, like anthracene or phenanthrene. Among the model compounds studied, furan produces the most condensed form of coke after catalytic pyrolysis. Combined with the liquid analysis shown in Figures 4, the structure of coke from furan is likely related to the formation of naphthalenes and PAHs during pyrolysis (furan pyrolysis has the highest selectivity to naphthalenes and PAHs, shown in Figure 4 (c)). The carbon formation pathway in R3C provides another explanation for the production of a more condensed structure of coke in catalytic pyrolysis of furan.
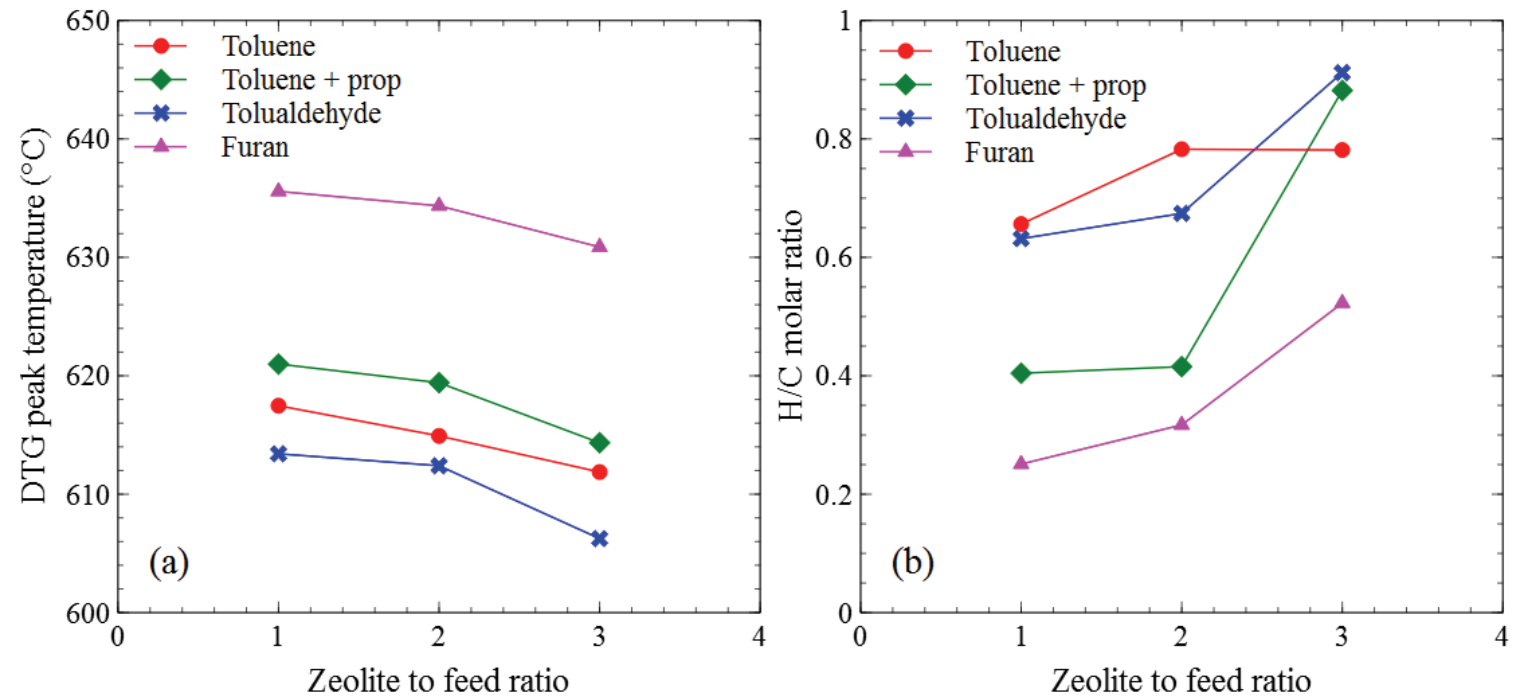

Figure 6. DTG peak temperature and H/C molar ratio of coked catalysts from different model compounds as a function of catalyst to feed ratio.

The aromatic structure of coke was further verified by elemental analysis, shown in Figure 6 (b). The H/C molar ratio of the pyrolysis coke increases with catalyst to feed ratio. This is consistent with the TPO results. All the coke samples have very low $\mathrm{H} / \mathrm{C}$ ratio in the range of $0.02-0.07$. For comparison, the smallest aromatic compound, benzene $\left(\mathrm{C}_{n} \mathrm{H}_{n}\right)$, has $\mathrm{H} / \mathrm{C}$ molar ratio of 0.08 . As the number of aromatic rings in the coke structure increases, the H/C molar ratio decreases. When the structure of coke becomes more carbonaceous (e.g., $\mathrm{C}_{2 n} \mathrm{H}_{n}$ ), the $\mathrm{H} / \mathrm{C}$ molar ratio 
reaches 0.04 . It is seen that coke from pyrolysis of furan has the lowest $\mathrm{H} / \mathrm{C}$ molar ratio (0.02), which indicates the highly hydrogen deficient structure in the coke from pyrolysis of furan. On the contrary, the coke from tolualdehyde at 3:1 catalyst to feed ratio has the highest $\mathrm{H} / \mathrm{C}$ molar ratio of about 0.07 .
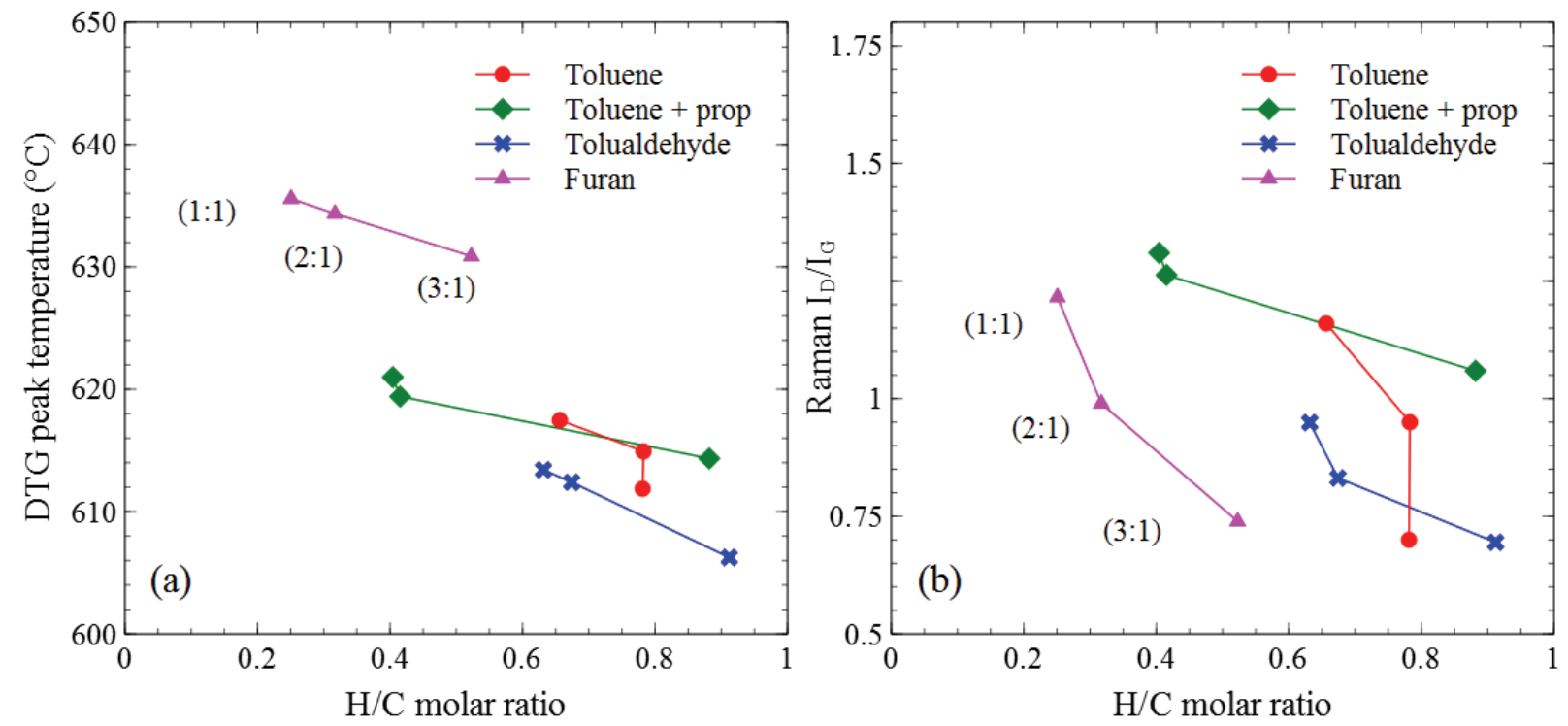

Figure 7. DTG peak temperature and Raman $\mathrm{I}_{\mathrm{D}} / \mathrm{I}_{\mathrm{G}}$ ratio as a function of the H/C molar ratio of coke in catalysts from pyrolysis of different model compounds.

A correlation between the DTG peak temperature and the H/C ratio is shown in Figure 7 (a), where it is clear that coke from pyrolysis of furan has much higher DTG peak temperature and lower H/C molar ratio, compared with the coke from pyrolysis of the other three model compounds, indicating a more condensed structure. The coke from toluene and tolualdehyde is of very similar structure. This further verifies that the formation of coke in the catalytic pyrolysis of either toluene or tolualdehyde follows similar reaction pathways, likely involving R2A of Scheme 2. Agreement is also reached by plotting the Raman ID/IG versus the H/C molar ratio, shown in Figure 7 (b). The ratio of the two bands, $\mathrm{I}_{\mathrm{D}} / \mathrm{I}_{\mathrm{G}}$, decreases for every model compound as the catalyst to feed ratio increases. This indicates more crystalline structures in the coke produced from pyrolysis with increasing catalyst to feed ratio regardless of the feed. The same conclusion can be drawn by studying the in-plane crystallite size (Table S3). Moreover, it is interesting that the crystallinity of coke from each model compound is increasing with the $\mathrm{H} / \mathrm{C}$ molar ratio. This means that as the structure of coke grows and becomes more condensed 
(more aromatic rings, lower $\mathrm{H} / \mathrm{C}$ ratio), more defects appear in the structure, leading to relatively disordered carbon structures.

\subsubsection{DRIFTS analysis}

In order to understand the most dominant bond types in the coke from the four model compounds, DRIFTS was performed, presented in Figure 8. Coke produced from pyrolysis of oxygenates (furan and tolualdehyde) does not contain oxygen in the form of carbonyl or hydroxyl groups. This is consistent with Scheme 3, R3A. In the region 3100-2900 cm-1, clear peaks are observed in the coke from pyrolysis of toluene and tolualdehyde, indicating that the coke from these two model compounds contains significant amounts of aliphatic carbons.

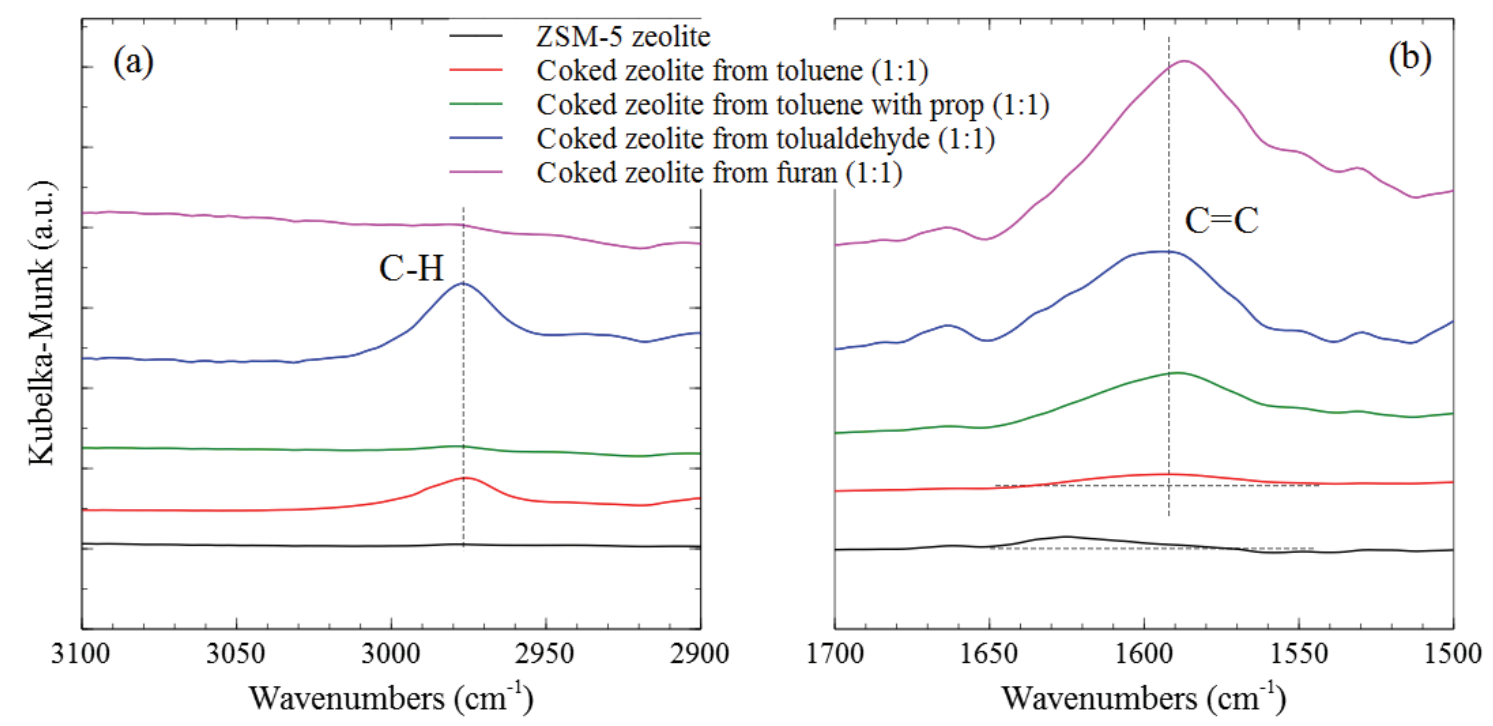

Figure 8. DRIFTS analysis of the coked catalysts from catalytic pyrolysis of different model compounds at $600{ }^{\circ} \mathrm{C}$, and 1:1 catalyst to feed ratio. Region $2900-3100 \mathrm{~cm}^{-1}$ represents sp $\mathrm{C}^{3} \mathrm{H}$ stretching; $1500-1700 \mathrm{~cm}^{-1} \mathrm{C}=\mathrm{C}$ stretching.

The presence of aliphatic carbons in the coke from pyrolysis of toluene and tolualdehyde is likely to be the reason for the higher $\mathrm{H} / \mathrm{C}$ ratio and lower temperature TPO peak, discussed previously. Coke from toluene with propylene does not contain aliphatic carbons, due to the enhancement of alkylation and cyclization reactions caused by the abundance of propylene and ethylene, shown in Figure 2. Coke from furan does not contain aliphatic carbons. This is consistent with Cheng and Huber [12], who suggested that there were no terminal methyl or methylene groups at $600{ }^{\circ} \mathrm{C}$ in the coke from catalytic pyrolysis of furan. In the DRIFTS spectra 
range of $1700-1500 \mathrm{~cm}^{-1}$, the coke samples from all the model compounds show peaks, characteristic of aromatic rings, although the peak of toluene coke is weak compared to others. Overall, these results indicate that the polyaromatic bone structure of coke is controlled by the ZSM-5 (its acidity and pore structure), whereas the aliphatic carbons in coke are reactantdependent.

\subsubsection{Solid-State ${ }^{13}$ C NMR analysis}

Figure 9 shows the ${ }^{13} \mathrm{C}$ NMR of the coked catalysts after pyrolysis of all the model compounds at 1:1 catalyst to feed ratio. According to the literature [73-75], the peak at 110-130 ppm represents non-substituted aromatic carbons; 130-140 represents carbon bridges between aromatic rings; $140-150$ ppm represents substituted aromatic carbon; and the peak at 40-55 ppm represents aliphatic carbons. Coke produced from catalytic pyrolysis of toluene and tolualdehyde has a clear peak at 40-55 ppm, which means that it contains measurable amounts of aliphatic carbons. However, coke from catalytic pyrolysis of furan and toluene co-feeding with propylene do not show aliphatic carbon shifts. The NMR results, showing the presence of aliphatic carbons in the coke produced from pyrolysis of toluene and tolualdehyde, are very consistent with those in DRIFTS. These observations mean that, during pyrolysis in the presence of olefins, the formation of coke is very likely to follow the reaction mechanism R1E, leading to a heavily condensed PAH coke structure without aliphatic carbons. 


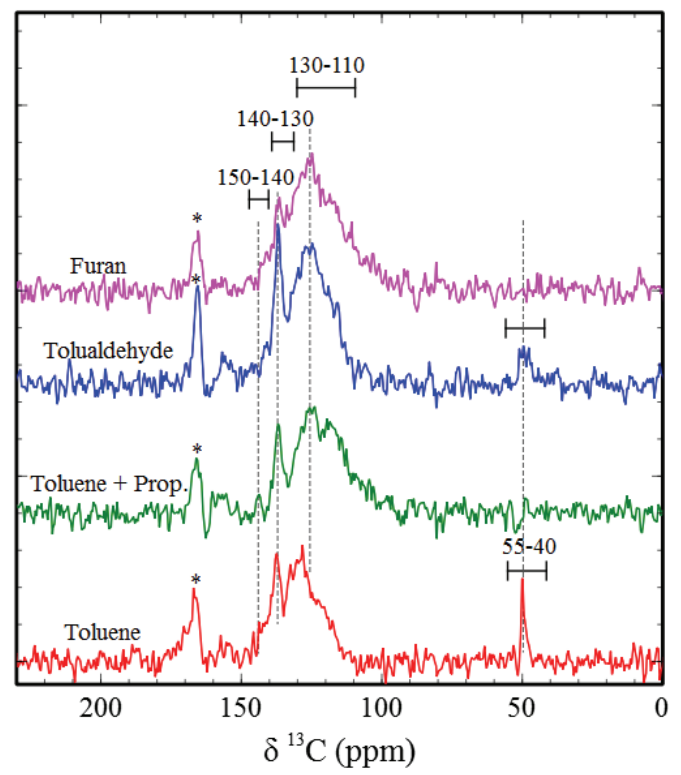

Figure 9. Solid-state ${ }^{13} \mathrm{C}$ NMR analysis of coked catalysts from catalytic pyrolysis of toluene, toluene/propylene, tolualdehyde and furan using ZSM-5 at $600{ }^{\circ} \mathrm{C}$ and $1: 1$ catalyst to feed ratios. "**" represents the spinning side bands; 110-130 ppm represents non-substituted aromatic carbon; 130-140 repre-sents carbon bridges between aromatic rings; 140-150 ppm represents substituted aromatic carbon; 55-40 ppm represents aliphatic carbon.

In Table 2, the NMR peak areas of the functional groups identified in the coked catalysts are compared quantitatively. Furan and toluene/propylene produce coke with $100 \%$ aromaticity (pure PAHs structure), whereas the coke from toluene and tolualdehyde have aliphatic carbons. It is interesting and important to understand what kind of aliphatic carbons exist in the toluene coke. In order to further understand the NMR results, the elemental analysis and ${ }^{13} \mathrm{C}$ NMR of various PAHs are predicted using the software Marvin from ChemAxon [76]. In this analysis, pyrene was used as the starting model compound since its accommodation in the ZSM-5 channels was confirmed previously $[77,78]$. Table 3 shows a summary of the elemental analyses, minimum and maximum molecular projection diameters, and NMR chemical shifts of pyrene and pyrene-derived model compounds. More detailed information regarding Table 3 is provided in Table S4. As shown in Table 3, pyrene does not contain aliphatic carbons. As its alkyl side chain becomes longer (from methyl group to ethyl group), the NMR peak shifts from $20 \mathrm{ppm}$ to $26 \mathrm{ppm}$. The change here is significant. However, the alkyl side chain cannot extend any longer (e.g. propyl group) in order to reach a 50 ppm NMR peak, because it would have been easier to form rings (Mechanism R1E) or be cracked to alkanes/alkenes in the presence of 
the zeolite catalyst [79]. Thus, further exploration focuses on the aliphatic carbon within the ring.

Table 2: Quantitative NMR analyses of coke from catalytic pyrolysis of model compounds (1:1 catalyst to feed ratio) ${ }^{*}$

\begin{tabular}{lccccc}
\hline & $\begin{array}{c}\text { Aliphatic } \\
\text { carbon }\end{array}$ & $\begin{array}{c}\text { Non-substituted } \\
\text { aromatic carbon }\end{array}$ & $\begin{array}{c}\text { Carbon bridges } \\
\text { between } \\
\text { aromatic rings } \\
130-140\end{array}$ & $\begin{array}{c}\text { Substituted } \\
\text { aromatic } \\
\text { carbon }\end{array}$ & Aromaticity \\
Location $(\mathrm{ppm})$ & $45-55$ & $110-130$ & 37.86 & 9.83 & 92.75 \\
\hline Toluene $(1: 1)$ & 7.25 & 45.06 & 24.29 & 0.00 & 100.0 \\
Toluene/propylene $(1: 1)$ & 0.00 & 75.71 & 30.32 & 6.02 & 95.32 \\
Tolualdehyde (1:1) & 4.68 & 58.98 & 28.85 & 0.00 & 100.0 \\
Furan (1:1) & 0.00 & 71.15 & & \\
\hline
\end{tabular}

${ }^{*}$ All values reported for aliphatic, non-substituted aromatic and alkyl-substituted aromatic carbons are area percentages of the total spectra area. Aromaticity means the total aromatic area percentage of the total spectra area.

In Table 3, a representative molecule with aliphatic carbons (noted with numbers) in the ring system (noted here as compound A for brevity) is shown. The predicted aliphatic peak in the NMR of compound $A$ is very close to the real experimental value (45-55 ppm). The accommodation of methylpyrene in the ZSM-5 pore system has been proven in the literature $[77,78]$. Thus, with a similar diameter, compound A can tightly fit inside the ZSM-5 channel intersections. It should be noted that further lateral growth of compound $\mathrm{A}$ in order to reach a more condensed structure (smaller $\mathrm{H} / \mathrm{C}$ molar ratio) is unlikely due to the shape selectivity theory $[7,80-83]$. Thus, this study proposes a linear growth of compound A to represent coke components with more condensed structures. Linear polyaromatic hydrocarbons have been found to sterically fit inside ZSM-5 pore systems. Palumbo et al. [84] studied the conversion of methanol to hydrocarbons over ZSM-5. They found that, during the reaction, PAHs, such as pentacene, can be trapped inside the ZSM-5 channels. Similarly, the tight fit of tetracene in ZSM-5 channels has been shown by Marquis et al. [85].

Table 3: Elemental analysis and ${ }^{13} \mathrm{C}$ NMR analyses of model compounds predicted by ChemAxon Marvin*

\begin{tabular}{ccccccccc}
\hline Compound & $\begin{array}{c}\text { Toluene } \\
\text { coke }\end{array}$ & $\begin{array}{c}\text { Toluene } \\
\text { /propyle } \\
\text { ne coke }\end{array}$ & $\begin{array}{c}\text { Tolualde } \\
\text { hyde } \\
\text { coke }\end{array}$ & $\begin{array}{c}\text { Furan } \\
\text { coke }\end{array}$ & Pyrene & $\begin{array}{c}\text { 1-Methyl- } \\
\text { pyrene }\end{array}$ & $\begin{array}{c}\text { 1-Ethyl- } \\
\text { pyrene }\end{array}$ & $A^{* * *}$ \\
\hline
\end{tabular}




\begin{tabular}{|c|c|c|c|c|c|c|c|c|c|}
\hline Structure & - & - & - & - & & & & & \\
\hline $\operatorname{MPD}^{* *}(\AA)$ & - & - & - & - & 9.48 & 9.50 & 9.64 & 9.48 & 9.50 \\
\hline $\begin{array}{l}\mathrm{H} / \mathrm{C} \text { molar } \\
\text { ratio }\end{array}$ & 0.055 & 0.034 & 0.053 & 0.021 & 0.052 & 0.059 & 0.065 & 0.053 & 0.051 \\
\hline $\begin{array}{l}\text { NMR } \\
\text { aromatic } \\
\text { carbon (ppm) }\end{array}$ & $110-150$ & $110-150$ & $110-150$ & $110-150$ & $125-131$ & $124-132$ & $124-140$ & $121-140$ & $114-148$ \\
\hline $\begin{array}{l}\text { NMR } \\
\text { aliphatic } \\
\text { carbon (ppm) }\end{array}$ & $45-55$ & - & $45-55$ & - & - & 20 & 15,26 & 46,47 & 47,48 \\
\hline
\end{tabular}

* The carbons in red represent the bridge carbons.

** MPD represents minimum projection diameter, as predicted by Marvin Sketch on the basis of the Van der Waals radius.

*** A: hexacyclo[11.7.1.14 $\left.{ }^{20} \cdot 0^{2},{ }^{11} \cdot 0^{3}, 8 \cdot 0^{17},{ }^{21}\right]$ docosa-2,4,6,8,10,12,14,16,18,20(22)-decaene

B:

decacyclo[14.14.2.14 $\left.{ }^{30} .1^{15}, 1^{19} \cdot 0^{2},{ }^{11} \cdot 0^{3},{ }^{8} \cdot 0^{13},{ }^{31} \cdot 0^{17},{ }^{26} .0^{18},{ }^{23} .0^{28},{ }^{32}\right]$ tetratriaconta-1(31),2,4(33),5,7,9,11,13,15(34),17,19,21,23,25,27, 29-hexadecaene

In Table 3, another PAH compound (noted here as compound B) represents a more condensed form (smaller $\mathrm{H} / \mathrm{C}$ molar ratio) than compound $\mathrm{A}$. It is clear that when compound $\mathrm{B}$ is used to represent coke, the aliphatic NMR bond shift drops exactly in the range of $45-55 \mathrm{ppm}$. This implies that the aliphatic carbon in coke observed in NMR and DRIFTS should have features similar to that of compound B. The aliphatic carbons exist mainly in the form of cyclic alkanes fused within aromatic rings in the structure of coke produced from pyrolysis of toluene and tolualdehyde at $600{ }^{\circ} \mathrm{C}$ and 1:1 catalyst to feed ratio. The H/C molar ratio of the model compounds shown here are in the range of 0.05-0.07, within the range measured from elemental analyses of the coke (0.02-0.07). Nonetheless, the model compounds shown in Table 3 (A and B) are most likely a few compounds of a mixture of condensed structures that comprise coke. 


\section{CONCLUSIONS}

In summary, reaction pathways for coke formation were studied in the thermal pyrolysis and ZSM-5-catalyzed pyrolysis of toluene, toluene/propylene, tolualdehyde and furan. The structure of coke from different model compounds was explored and compared to each other. From the experimental results and corresponding discussion, the following main conclusions were drawn:

- The production of coke is affected by the catalyst to feed ratio, reflecting the catalytic origin of the coke. It is also highly dependent on the model compounds, since the contribution of thermal reactions to the solid yields during catalytic pyrolysis differs among model compounds.

- In toluene catalytic pyrolysis, coke formation follows alkylation reaction pathways. Biphenyls, bibenzyl and heavy PAHs are important reaction intermediates leading to coke formation. The co-feeding of toluene with propylene does not enhance coke formation. Propylene mostly forms toluene/benzene as the primary step and follows the alkylation reactions of toluene/benzene afterwards.

- In catalytic pyrolysis of tolualdehyde (used as a representative aromatic oxygenate), decarbonylation was shown as the initial step during the pyrolysis. The formation of catalytic coke follows the same path as that in the catalytic pyrolysis of toluene. The formation of thermal coke is promoted by the presence of the tolualdehyde formyl group, which leads to radical thermal reaction pathways for thermal coke formation.

- In catalytic pyrolysis of furan, Diels-Alder, hydrolysis and furan self-condensation reactions for the production of olefins and aromatic hydrocarbons are the dominant reactions. The aromatic hydrocarbons and olefins in the "hydrocarbon pool" were seen as coke precursors leading to coke of polyaromatic structure. Furan self-condensation reactions followed by decarbonylation and cracking, lead to more carbonaceous coke with highly condensed structure.

- The structure of coke is similar between toluene and tolualdehyde, which is consistent with their proposed pyrolysis mechanisms. In pyrolysis of tolualdehyde and toluene, coke 
contains aliphatic carbons in its aromatic ring system. No aliphatic carbons were observed in the coke after catalytic pyrolysis of toluene/propylene co-feeding and furan.

\section{ACKNOWLEDGMENTS}

This work was supported by the National Science Foundation under Grant No. CBET 1236738. 


\section{REFERENCES}

[1] C.-H. Zhou, X. Xia, C.-X. Lin, D.-S. Tong, J. Beltramini, Chem. Soc. Rev. 40 (2011) 5588617.

[2] G.W. Huber, S. Iborra, A. Corma, Chem. Rev. 106 (2006) 4044-4098.

[3] S. Du, Y. Sun, D.P. Gamliel, J.A. Valla, G.M. Bollas, Bioresour. Technol. 169 (2014) 188197.

[4] D.P. Gamliel, S. Du, G.M. Bollas, J.A. Valla, Bioresour. Technol. 191 (2015) 187-196.

[5] A. Fischer, S. Du, J.A. Valla, G.M. Bollas, RSC Adv. 5 (2015) 29252-29261.

[6] I. Noshadi, B. Kanjilal, S. Du, G.M. Bollas, S.L. Suib, A. Provatas, F. Liu, R.S. Parnas, Appl. Energy 129 (2014) 112-122.

[7] J. Jae, G.A. Tompsett, A.J. Foster, K.D. Hammond, S.M. Auerbach, R.F. Lobo, G.W. Huber, J. Catal. 279 (2011) 257-268.

[8] A. Aho, N. Kumar, K. Eränen, T. Salmi, M. Hupa, D.Y. Murzin, Fuel 87 (2008) 2493-2501.

[9] S.D. Stefanidis, K.G. Kalogiannis, E.F. Iliopoulou, A.A. Lappas, P.A. Pilavachi, Bioresour. Technol. 102 (2011) 8261-7.

[10] S. Du, J.A. Valla, G.M. Bollas, Green Chem. 15 (2013) 3214.

[11] B. Valle, P. Castaño, M. Olazar, J. Bilbao, A.G. Gayubo, J. Catal. 285 (2012) 304-314.

[12] Y.-T. Cheng, G.W. Huber, ACS Catal. 1 (2011) 611-628.

[13] M. Guisnet, P. Magnoux, Appl. Catal. A Gen. 212 (2001) 83-96.

[14] D. Fabbri, A.G. Rombolà, C. Torri, K.A. Spokas, J. Anal. Appl. Pyrolysis 103 (2013) 60-67.

[15] C.E. Brewer, K. Schmidt-Rohr, J.A. Satrio, R.C. Brown, Environ. Prog. Sustain. Energy 28 (2009) 386-396.

[16] L. Hora, V. Kelbichová, O. Kikhtyanin, O. Bortnovskiy, D. Kubička, Catal. Today 223 (2014) 138-147. 
[17] S. Mani, J.R. Kastner, A. Juneja, Fuel Process. Technol. 114 (2013) 118-125.

[18] F. Lannuzel, R. Bounaceur, R. Michels, G. Scacchi, P.-M. Marquaire, J. Anal. Appl. Pyrolysis 87 (2010) 236-247.

[19] T. Odedairo, R.J.J. Balasamy, S. Al-Khattaf, J. Mol. Catal. A Chem. 345 (2011) 21-36.

[20] H.S. Cerqueira, G. Caeiro, L. Costa, F. Ramôa Ribeiro, J. Mol. Catal. A Chem. 292 (2008) $1-13$.

[21] R. Quintana-Solórzano, J.W. Thybaut, G.B. Marin, R. Lødeng, A. Holmen, Catal. Today 107-108 (2005) 619-629.

[22] L. Zhang, J. Cai, T. Zhang, F. Qi, Combust. Flame 157 (2010) 1686-1697.

[23] A. Matsugi, A. Miyoshi, Proc. Combust. Inst. 34 (2013) 269-277.

[24] M.B. Colket, D.J. Seery, Twenty-Fifth Symp. Combust. (1994) 883-891.

[25] Y.-T. Cheng, G.W. Huber, Green Chem. 14 (2012) 3114.

[26] T. Prasomsri, A.T. To, S. Crossley, W.E. Alvarez, D.E. Resasco, Appl. Catal. B Environ. 106 (2011) 204-211.

[27] C.A. Mullen, A.A. Boateng, Fuel Process. Technol. 91 (2010) 1446-1458.

[28] T.R. Carlson, Y.-T. Cheng, J. Jae, G.W. Huber, Energy Environ. Sci. 4 (2011) 145.

[29] K.K. Ramasamy, M.A. Gerber, M. Flake, H. Zhang, Y. Wang, Green Chem. 16 (2014) 748760.

[30] T.Q. Hoang, X. Zhu, L.L. Lobban, D.E. Resasco, R.G. Mallinson, Catal. Commun. 11 (2010) 977-981.

[31] A.G. Gayubo, A.T. Aguayo, A. Atutxa, R. Aguado, M. Olazar, J. Bilbao, Ind. Eng. Chem. Res. 43 (2004) 2619-2626.

[32] X. Zhu, R.G. Mallinson, D.E. Resasco, Appl. Catal. A Gen. 379 (2010) 172-181.

[33] A. Ausavasukhi, T. Sooknoi, D.E. Resasco, J. Catal. 268 (2009) 68-78. 
[34] J.D. Adjaye, N.N. Bakhshi, Biomass and Bioenergy 8 (1995) 131-149.

[35] M. Bjorgen, S. Svelle, F. Joensen, J. Nerlov, S. Kolboe, F. Bonino, L. Palumbo, S. Bordiga, U. Olsbye, J. Catal. 249 (2007) 195-207.

[36] R. Vinu, L.J. Broadbelt, Energy Environ. Sci. 5 (2012) 9808.

[37] A. Aho, A. Tokarev, P. Backman, N. Kumar, K. Eränen, M. Hupa, B. Holmbom, T. Salmi, D.Y. Murzin, Top. Catal. 54 (2011) 941-948.

[38] X. Zhang, L. Sun, L. Chen, X. Xie, B. Zhao, H. Si, G. Meng, J. Anal. Appl. Pyrolysis 108 (2014) 35-40.

[39] D.J. Nowakowski, A.V. Bridgwater, D.C. Elliott, D. Meier, P. de Wild, J. Anal. Appl. Pyrolysis 88 (2010) 53-72.

[40] C.E. Greenhalf, D.J. Nowakowski, N. Yates, I. Shield, A.V. Bridgwater, Biomass and Bioenergy 56 (2013) 247-259.

[41] H.J. Park, K.-H. Park, J.-K. Jeon, J. Kim, R. Ryoo, K.-E. Jeong, S.H. Park, Y.-K. Park, Fuel 97 (2012) 379-384.

[42] M. Asmadi, H. Kawamoto, S. Saka, J. Anal. Appl. Pyrolysis 92 (2011) 88-98.

[43] A.G. Gayubo, A.T. Aguayo, A. Atutxa, R. Aguado, M. Olazar, J. Bilbao, Ind. Eng. Chem. Res. 43 (2004) 2619-2626.

[44] E.F. Iliopoulou, S.D. Stefanidis, K.G. Kalogiannis, A. Delimitis, A.A. Lappas, K.S. Triantafyllidis, Appl. Catal. B Environ. 127 (2012) 281-290.

[45] R.N. Widyaningrum, T.L. Church, A.T. Harris, Catal. Commun. 35 (2013) 45-50.

[46] R.N. Hilten, K.C. Das, Fuel 89 (2010) 2741-2749.

[47] P.K. Chu, L. Li, Mater. Chem. Phys. 96 (2006) 253-277.

[48] P. Matousek, M. Towrie, A.W. Parker, J. Raman Spectrosc. 33 (2002) 238-242.

[49] X. Li, C. Li, J. Zhang, C. Yang, H. Shan, J. Nat. Gas Chem. 16 (2007) 92-99. 
[50] F. Seyedeyn-Azad, E. Salehi, J. Abedi, T. Harding, Fuel Process. Technol. 92 (2011) 563569.

[51] X. Meng, C. Xu, J. Gao, Fuel 86 (2007) 1720-1726.

[52] E. Pütun, B.B. Uzun, A.E. Putün, Energy and Fuels 23 (2009) 2248-2258.

[53] G.M. Bollas, A.A. Lappas, D.K. Iatridis, I.A. Vasalos, Catal. Today 127 (2007) 31-43.

[54] G.M. Bollas, I.A. Vasalos, A.A. Lappas, D.K. Iatridis, S.S. Voutetakis, S.A. Papadopoulou, Chem. Eng. Sci. 62 (2007) 1887-1904.

[55] E.L. First, C.E. Gounaris, J. Wei, C.A. Floudas, Phys. Chem. Chem. Phys. 13 (2011) 1733958.

[56] P. Prokešová, N. Žilková, S. Mintova, T. Bein, J. Čejka, Appl. Catal. A Gen. 281 (2005) 8591.

[57] J. Rigoreau, S. Laforge, N. Gnep, M. Guisnet, J. Catal. 236 (2005) 45-54.

[58] C.D. Hurd, C.W. Bennett, J. Am. Chem. Soc. 44 (1929) 1197-1201.

[59] A.K. Vasiliou, J.H. Kim, T.K. Ormond, K.M. Piech, K.N. Urness, A.M. Scheer, D.J. Robichaud, C. Mukarakate, M.R. Nimlos, J.W. Daily, Q. Guan, H.-H. Carstensen, G.B. Ellison, J. Chem. Phys. 139 (2013) 104310.

[60] S. Kamiguchi, S. Nishida, I. Takahashi, H. Kurokawa, H. Miura, T. Chihara, J. Mol. Catal. A Chem. 255 (2006) 117-122.

[61] M.S. Mettler, D.G. Vlachos, P.J. Dauenhauer, Energy Environ. Sci. 5 (2012) 7797-7809.

[62] I. van Zandvoort, Y. Wang, C.B. Rasrendra, E.R.H. van Eck, P.C.A. Bruijnincx, H.J. Heeres, B.M. Weckhuysen, ChemSusChem 6 (2013) 1745-1758.

[63] S.K.R. Patil, C.R.F. Lund, Energy \& Fuels 25 (2011) 4745-4755.

[64] N. Li, G.A. Tompsett, T. Zhang, J. Shi, C.E. Wyman, G.W. Huber, Green Chem. 13 (2011) 91-101.

[65] T.R. Carlson, J. Jae, Y.-C. Lin, G.A. Tompsett, G.W. Huber, J. Catal. 270 (2010) 110-124. 
[66] S. Vaitheeswaran, S.K. Green, P. Dauenhauer, S.M. Auerbach, ACS Catal. 3 (2013) 20122019.

[67] M. Stöcker, Microporous Mesoporous Mater. 29 (1999) 3-48.

[68] D.M. McCann, D. Lesthaeghe, P.W. Kletnieks, D.R. Guenther, M.J. Hayman, V. Van Speybroeck, M. Waroquier, J.F. Haw, Angew. Chemie - Int. Ed. 47 (2008) 5179-5182.

[69] C.J. Gilbert, J.S. Espindola, W.C. Conner, J.O. Trierweiler, G.W. Huber, ChemCatChem (2014).

[70] M. Lezanska, P. Pietrzyk, Z. Sojka, J. Phys. Chem. C 114 (2010) 1208-1216.

[71] J. Schwan, S. Ulrich, V. Batori, H. Ehrhardt, J. Appl. Phys. 80 (1996).

[72] A.C. Ferrari, J. Robertson, Phys. Rev. B 61 (2000) 95-107.

[73] S. Jong, A.R. Pradhan, J. Wu, T. Tsai, S. Liu, J. Catal. 174 (1998) 210-218.

[74] M. Callejas, M.T. Martínez, T. Blasco, E. Sastre, Appl. Catal. A Gen. 218 (2001) 181-188.

[75] A.R.A. Pradhan, J.J.F. Wu, S.J.S. Jong, T.C.T. Tsai, S.B.S. Liu, Appl. Catal. A Gen. 165 (1997) 489-497.

[76] ChemAxon, Http://www.chemaxon.com/ (2015).

[77] D. Mores, J. Kornatowski, U. Olsbye, B.M. Weckhuysen, Chem. - A Eur. J. 17 (2011) 28742884.

[78] M. Guisnet, P. Magnoux, Appl. Catal. A, Gen. 54 (1989) 1-27.

[79] X. Dupain, E.D. Gamas, R. Madon, C.P. Kelkar, M. Makkee, J.A. Moulijn, Fuel 82 (2003) 1559-1569.

[80] Y. Yu, X. Li, L. Su, Y. Zhang, Y. Wang, H. Zhang, Appl. Catal. A Gen. 447-448 (2012) 115123.

[81] C. Fernandez, I. Stan, J.-P. Gilson, K. Thomas, A. Vicente, A. Bonilla, J. Pérez-Ramírez, Chemistry 16 (2010) 6224-33. 
[82] B.P.C. Hereijgers, F. Bleken, M.H. Nilsen, S. Svelle, K.-P. Lillerud, M. Bjørgen, B.M. Weckhuysen, U. Olsbye, J. Catal. 264 (2009) 77-87.

[83] B. Smit, T.L.M. Maesen, Nature 451 (2008) 671-8.

[84] L. Palumbo, F. Bonino, P. Beato, M. Bjørgen, A. Zecchina, S. Bordiga, J. Phys. Chem. C 112 (2008) 9710-9716.

[85] S. Marquis, A. Moissette, M. Hureau, H. Vezin, C. Brémard, J. Phys. Chem. C 111 (2007) 17346-17356. 
